\title{
ORIGINAL ARTICLE JNKs function as CDK4-activating kinases by phosphorylating CDK4 and p21
}

\author{
B Colleoni ${ }^{1,4}$, S Paternot ${ }^{1,4}$, JM Pita ${ }^{1}$, X Bisteau $^{1,5}, \mathrm{~K}$ Coulonval $^{1}$, RJ Davis ${ }^{2,3}$, E Raspé ${ }^{1}$ and PP Roger ${ }^{1}$
}

Cyclin D-CDK4/6 are the first cyclin-dependent kinase (CDK) complexes to be activated by mitogenic/oncogenic pathways. They have a central role in the cell multiplication decision and in its deregulation in cancer cells. We identified T172 phosphorylation of CDK4 rather than cyclin D accumulation as the distinctly regulated step determining CDK4 activation. This finding challenges the view that the only identified metazoan CDK-activating kinase, cyclin H-CDK7-Mat1 (CAK), which is constitutively active, is responsible for the activating phosphorylation of all cell cycle CDKs. We previously showed that T172 phosphorylation of CDK4 is conditioned by an adjacent proline (P173), which is not present in CDK6 and CDK1/2. Although CDK7 activity was recently shown to be required for CDK4 activation, we proposed that proline-directed kinases might specifically initiate the activation of CDK4. Here, we report that JNKs, but not ERK1/2 or CAK, can be direct CDK4-activating kinases for cyclin D-CDK4 complexes that are inactivated by p21-mediated stabilization. JNKs and ERK1/2 also phosphorylated p21 at S130 and T57, which might facilitate CDK7-dependent activation of p21-bound CDK4, however, mutation of these sites did not impair the phosphorylation of CDK4 by JNKs. In two selected tumor cells, two different JNK inhibitors inhibited the phosphorylation and activation of cyclin D1-CDK4-p21 but not the activation of cyclin D3-CDK4 that is mainly associated to p27. Specific inhibition by chemical genetics in MEFs confirmed the involvement of JNK2 in cyclin D1-CDK4 activation. Therefore, JNKs could be activating kinases for cyclin D1-CDK4 bound to p21, by independently phosphorylating both CDK4 and p21.

Oncogene (2017) 36, 4349-4361; doi:10.1038/onc.2017.7; published online 3 April 2017

\section{INTRODUCTION}

The eukaryotic cell cycle depends on the sequential formation and activation of different cyclin-dependent kinase (CDK) complexes. ${ }^{1,2}$ In response to the mitogenic/oncogenic signaling, cell cycle commitment at the restriction (R) point in the $\mathrm{G} 1$ phase is initiated by inactivating phosphorylations of the central cell cycle/tumor suppressor Rb by CDK4 and CDK6. ${ }^{3-5} \mathrm{Rb}$ phosphorylation is maintained by a positive-feedback loop linking $\mathrm{Rb}$ to E2F-dependent transcription of cyclin $E$, that in turn activates CDK2 and leads to further phosphorylation of Rb. ${ }^{6}$ This feedback, coupled with self-induction of E2F and mutual inhibition between cyclin E-CDK2 and p27 ${ }^{\text {Kip } 1}$, generates a bistable Rb-E2F switch that converts graded mitogen inputs into all-or-none E2F responses and finally into the cell cycle commitment. ${ }^{7}$ Because the frequent deregulation of CDK4 in cancer often leads to addiction to its activity, CDK4 is emerging as a particularly promising therapeutic target. $^{8-11}$ Specific CDK4/6 inhibitors are being tested against most cancers ${ }^{12,13}$ and PD0332991 (Palbociclib) received a first approval by the FDA as a first-line treatment combined with endocrine therapy of advanced breast cancers. ${ }^{12}$

The activation of CDK4 differs from the activation of the other cell cycle CDKs in several respects. It requires the binding to a D-type cyclin, which is opposed by INK4 CDK inhibitors such as p16, and then an activating phosphorylation in the T-loop at T172. ${ }^{5,14-16}$ However, in contrast to CDK2 and CDK1, ${ }^{17}$
CDK4 activation is not restricted by stoichiometric inhibitory phosphorylations. ${ }^{5,14,15}$ Moreover, we found in a variety of cell models and regulations that its activating phosphorylation is highly regulated, determining CDK4 activity. ${ }^{15,18-23}$ The effects of p21 and p27 on CDK4/6 activation are complex and remain debated. p21 is the main transcriptional target involved in replicative senescence and p53-dependent cell cycle inhibition in response to DNA damage, however, it is also transiently induced by mitogenic stimuli. ${ }^{24}$ Although p21 and p27 potently inhibit CDK2, they stabilize cyclin D-CDK4/6 complexes and target them to nuclei, but they can also inhibit CDK4/6 activity. ${ }^{15,25,26}$ How can p21 and p27 shift from an inhibitory to an activation mode is still debated. One possibility is related to differences in the stoichiometry of the binding of these proteins to cyclin-CDK complexes. ${ }^{15,25,27}$ Phosphorylations of p21 and p27 have also emerged as potential mechanisms for CDK regulation. ${ }^{28-31}$ We recently demonstrated that S130 phosphorylation of p21 inside the cyclin D-CDK4/6 complexes is catalyzed by other active CDK4/6 and CDK2 complexes, and is required for CDK7-dependent T172 phosphorylation of p21-bound CDK4 complexes. ${ }^{23}$

The distinct and critical regulation of CDK4 T172 phosphorylation sharply contrasts with the prevalent 'textbook' concept stating that the CDK-activating kinase (CAK, formed by the nuclear cyclin H-CDK7-Mat1 complex) is the only kinase performing the activating phosphorylations in the T-loops of the different CDKs,

\footnotetext{
${ }^{1}$ WELBIO, Institute of Interdisciplinary Research (IRIBHM) and ULB-Cancer Research Center (U-CRC), Université Libre de Bruxelles, Brussels, Belgium; ${ }^{2}$ Program in Molecular Medicine, University of Massachusetts Medical School, Worcester, MA, USA and ${ }^{3}$ Howard Hughes Medical Institute, Worcester, MA, USA. Correspondence: Dr PP Roger, IRIBHM, Université Libre de Bruxelles, Campus Erasme, 808 Route de Lennik, Brussels B-1070 Belgium.

E-mail: proger@ulb.ac.be

${ }^{4}$ These authors contributed equally to this work.

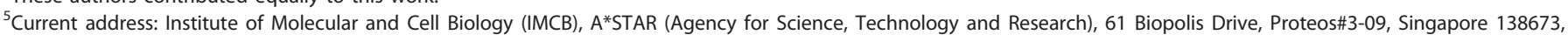
Republic of Singapore.

Received 19 August 2016; revised 16 December 2016; accepted 11 January 2017; published online 3 April 2017
} 
including CDK4 and CDK6. ${ }^{32-34}$ CAK is constitutively active and weakly or not regulated during the cell cycle and in response to mitogenic stimulations, ${ }^{15,35}$ even when assayed on CDK4 complexes. ${ }^{19,20,23,36}$ The regulation of CDK4 phosphorylation is partially different for cyclin D1-CDK4 and cyclin D3-CDK4. ${ }^{20,37,38}$ Moreover, it affects CDK4 but not the much related CDK6, which is poorly phosphorylated and active in several cells. ${ }^{15,21}$ We explained this difference by the absence of a conserved adjacent proline that is uniquely present in the phospho-acceptor domain of CDK4 (QMALTPVVVT in CDK4 versus QMALTSVVVT in CDK6). ${ }^{21}$ Indeed, mutations of proline 173 did not adversely affect cyclin D3-CDK4 activation by CAK in vitro, but in cells these mutations abolished CDK4 T172 phosphorylation and activity. Conversely, substituting a proline to the corresponding serine 178 of CDK6 enforced its complete T177 phosphorylation and dramatically increased its activity. ${ }^{21}$ These results, together with the fact that CDK4 is a poor substrate of CAK in vitro in comparison with other CDKs including CDK6, ${ }^{15,21,39,40}$ led us to propose that in intact cells CDK4 might not be phosphorylated by CDK7, but more likely by other, presumably proline-directed, kinase(s) (PDKs). ${ }^{16,21}$ Nevertheless, cyclin H-CDK7-Mat1 phosphorylates several nonCDK substrates at T/S-P motifs and might be considered as a 'conditional' PDK. ${ }^{40}$ More recent experiments by our group and the Rob Fisher lab using HCT116 cells engineered to express an 'analog-sensitive' version of CDK7 that can be selectively inhibited ${ }^{41}$ demonstrated in these specific cells that the involvement of CDK7 in CDK4 activation is crucial, ${ }^{23,33}$ as well as unexpectedly complex and partly indirect, ${ }^{23}$ and that non-CDK7 CDK4-activating kinase(s) exist. ${ }^{23}$

In this study, we sought to identify new CDK4-activating kinases. S/T-P motifs (such as T172 of CDK4 and S130 of p21) are more likely to be phosphorylated by several PDKs. ${ }^{42}$ The kinome comprises about 70 PDKs (our Phosphosite database analysis). Most of them belong to the CDK/MAPK/GSK3/CLK group, which includes MAPKs, CDKs, GSKs, HIPKs and subfamilies related to MAPKs and CDKs. We reasoned that CDK4-activating kinase candidates should be required for G1 phase progression in some cells, and, in addition, should interact with one of the proteins of the CDK4 complexes. C-Jun N-terminal kinases (JNKs; also known as SAPKs and MAPK8-10) $)^{43}$ are required for proliferation of some tumor cells ${ }^{44-47}$ and murine embryo fibroblasts (MEFs) ${ }^{48}$ and they are oncogenic in several tumor models. ${ }^{49-52}$ Moreover, JNKs bind p2 $1^{53-55}$ and JNK2 was identified as a CDK4 interactor in a yeast two-hybrid screen (patent US 5691147, CDK4 binding assay, Giulio Draetta and Jeno Gyuris, 1997). Here, we demonstrate that JNK1 and JNK2 could be bona fide activating kinases for p21-bound cyclin D1-CDK4, by independently phosphorylating CDK4 and p21.

\section{RESULTS}

JNK1 and JNK2 phosphorylate p21-bound CDK4 and p21 in vitro We first evaluated whether JNKs and other MAPKs could phosphorylate CDK4. As cyclin D-CDK4 complexes exist mostly during the G1 phase in interaction with p21 (which stabilizes them), cyclin D1-CDK4-p21 and cyclin D3-CDK4-p21 complexes were produced in $\mathrm{CHO}$ cells by transfecting the corresponding human cDNA expression vectors. The CDK4 complexes were immunoprecipitated (Ip) using antibodies directed against cyclin D1 or cyclin D3 and incubated with ATP and different recombinant kinases (Figure 1). The phosphorylation of CDK4 was revealed by immunodetection of phosphorylated and non-phosphorylated CDK4 forms separated by 2D-gel electrophoresis. ${ }^{15}$ Importantly, before incubation with kinases, CDK4 bound to p21 and cyclin D1 or cyclin D3 was only faintly phosphorylated in $\mathrm{CHO}$ cells that express high levels of p21. ${ }^{23}$ This was in contrast with the high CDK4 phosphorylation level observed when cyclin D3-CDK4 complexes were produced in the absence of a p21 expression vector (compare the 'no kinase' panels in Figures 1a and c). As shown in Figure 1a, JNK1, JNK2 and more weakly p38a efficiently phosphorylated CDK4 bound to p21 and cyclin D1 or cyclin D3. JNK3 only phosphorylated cyclin D1-bound CDK4. By contrast, ERK1 and ERK2 were unable to phosphorylate CDK4 in those conditions (Figure 1a). CDK4 was phosphorylated only on T172, as indicated by detection with a T172-phosphospecific antibody (Figure 1a) and by lack of phosphorylation of T172A CDK4 by JNK1 (Figure 1b).

In these experiments, recombinant CAK (cyclin H-CDK7-Mat1) was unable to phosphorylate CDK4 in cyclin D-CDK4 complexes bound to p21 (Figure 1a). However, the CAK preparation was active in the same experiments, as it efficiently phosphorylated cyclin D3-CDK4 complexes that were produced in CHO cells in the absence of p21 and dephosphorylated by $\lambda$-phosphatase (Figure 1c). JNK1 only faintly phosphorylated CDK4 in this last condition (Figure 1c), suggesting that the phosphorylation of CDK4 by JNK1 observed in Figure 1a required the binding of cyclin D3-CDK4 complexes to p21. As T170 phosphorylation of CDK7 was reported to be important for CDK4 phosphorylation by $\mathrm{CAK}_{1}^{33}$ we verified that CDK7 was fully phosphorylated at T170 in the CAK preparation, using 2D-gel electrophoresis and a T170phosphospecific antibody ${ }^{23}$ (not shown). Finally, we and others previously observed that activation and phosphorylation of cyclin D3-CDK4 by CAK in vitro is rather inefficient and requires millimolar concentrations of ATP, whereas lower ATP concentrations suffice for phosphorylating CDK2 and CDK6 in the same conditions. ${ }^{15,21,39}$ Here, JNKs phosphorylated p21-bound cyclin D-CDK4 at lower concentrations of ATP (50-250 $\mu \mathrm{m}$, Supplementary Figure S1). In conclusion, JNKs can phosphorylate CDK4 in various in vitro conditions that do not support phosphorylation of CDK4 by CAK.

In the same experiments, we observed that the different MAPKs, including JNK1-3, ERK1, ERK2 and p38a phosphorylated p21 inside the cyclin D1-CDK4 and cyclin D3-CDK4 complexes (Figure 2). p21 contains three S/T-P motifs (T57, S98, S130). Using 2D-gel separations, we previously characterized the migration of p21 forms comprising the phosphorylations at $\mathrm{S} 130$ and/or S98, which were performed in vitro by the different complexes of CDK4, CDK6 and CDK2. ${ }^{23}$ Here, we observed that the different MAPKs also phosphorylate S130 and S98 residues (Figure 2a), the identity of which was confirmed by the disappearance of the respective spots in S98A and S130A mutants (Supplementary Figure S2A, as also seen in Figure 3). We previously showed that the abundant S130 phosphorylation observed in p21 bound to cyclin D-CDK4 complexes is required for CDK7-dependent T172 phosphorylation of CDK4 inside these complexes. ${ }^{23}$ Therefore, S130 phosphorylation of p21 by the different MAPKs, including JNKs and ERKs, might facilitate the CAK-mediated activation of p21-bound cyclin D-CDK4. CAK also weakly phosphorylated p21 in those experiments, but not at S130, S98 or T57 (data not shown, also seen in Bisteau et al., $^{23}$ ).

We also analyzed the in vitro phosphorylation of p21 that was produced alone in $\mathrm{CHO}$ cells transfected with human p21 cDNA in the absence of expression vectors for CDK4 and cyclins D. In contrast to p21 bound to cyclin D-CDK4, 'free' p21 was phosphorylated by JNK2 and ERK2 not only at S130 and S98, but also and even more efficiently at T57 (Figure 2b; Supplementary Figure S2). As shown by detection of additional p21 spots in 2D-gel immunoblots, analysis of the phosphorylation of the T57A mutant and use of a T57-phosphospecific antibody, almost all detected p21 forms were phosphorylated at T57 after incubation with ERK2, JNK1 or JNK2 (Figure 2b; Supplementary Figure S2). The T57 residue lies within the CDK-binding domain of p21, ${ }^{56,57}$ which could explain why this residue was not effectively accessible for phosphorylation in p21-CDK4 complexes. Mutations in the CDK-binding domain of p21 increase the activity of p21-bound cyclin D-CDK4 complexes. ${ }^{58}$ Moreover, we previously 
a

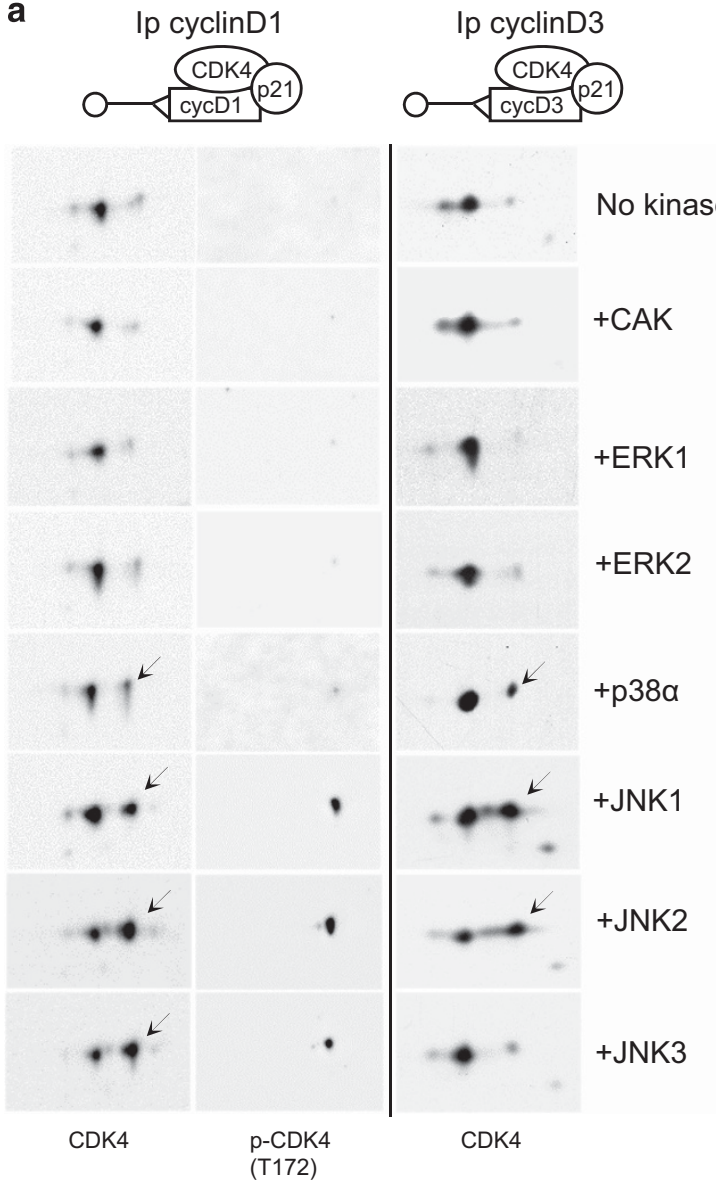

b

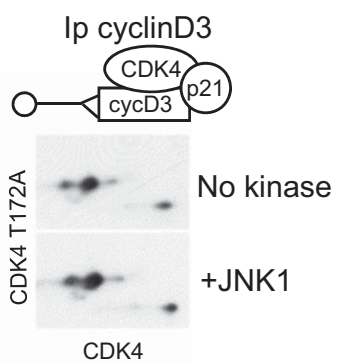

c

Ip cyclinD3

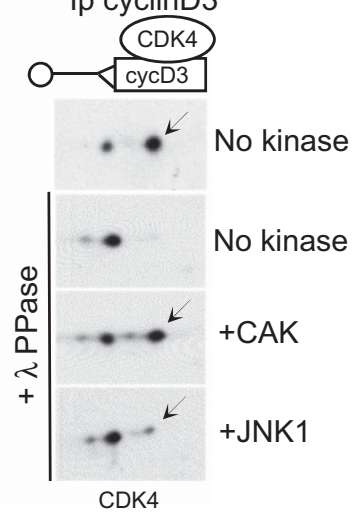

Figure 1. JNKs phosphorylate p21-bound CDK4 in vitro, but ERK1/2 and CAK do not. (a, b) CHO cells were transfected with plasmids encoding p21, cyclin D1 or cyclin D3 and CDK4 (a) or T172A CDK4 (b). Cell lysates were Ip with cyclin D1 or cyclin D3 antibodies. The co-immunoprecipitates were incubated with the indicated recombinant kinases and ATP, separated by 2D-gel electrophoresis, and immunodetected with antibodies against CDK4 or its T172 phosphorylation (p-CDK4(T172)). The experiment in a was reproduced four times using cyclin D1-CDK4-p21 complexes and three times using cyclin D3-CDK4-p21 complexes, with similar results. (c) As a positive control for CAK activity in the experiment shown in a, Ip cyclin D3-CDK4 complexes (Ip cyclin D3) from CHO cells transfected only with plasmids encoding CDK4 and cyclin D3 were incubated with ATP and CAK or JNK1, and analyzed by 2D-gel electrophoresis and CDK4 immunodetection. Because cyclin D3-CDK4 complexes produced in CHO cells in the absence of p21 expression are phosphorylated at T172, they were dephosphorylated by incubation with $\lambda$ phosphatase $(+\lambda$ PPase) before incubation with kinases (c). Black arrows indicate the increased abundance of the T172-phosphorylated form of CDK4.

observed that the phosphomimetic T57D mutation of p21 facilitates the T172 phosphorylation of p21-bound CDK4 by CAK in vitro (Supplementary Figure S8 in Bisteau et al., ${ }^{23}$ ). Therefore, we further evaluated whether T57 phosphorylation could also affect the activity and T172 phosphorylation of p21-bound CDK4 complexes in vivo. As shown in Figure $2 \mathrm{C}$ and Supplementary Figure S2C, the T57D mutation of p21 markedly increased in transfected $\mathrm{CHO}$ cells both the Rb-kinase activity and the phosphorylation of CDK4 in complexes Ip with p21, cyclin D1 or cyclin D3 antibodies.

On the basis of the above-described observations, phosphorylations of p21 at S130 and/or T57 by several MAPKs might facilitate the phosphorylation and activation of CDK4 complexes by CAK. So we evaluated whether they are similarly required for in vitro phosphorylation of p21-bound CDK4 by JNKs. Cyclin D1-CDK4 complexes containing wild-type p21 or each of its phosphorylation mutants were produced by transfection of $\mathrm{CHO}$ cells. As shown in Figure 3, none of these mutations of p21 including T57A, S130A, S98A and double mutation T57A/S130A impaired the in vitro phosphorylation of CDK4 by JNK1 and JNK2. Collectively, these experiments together with our previous observations indicate that JNKs might activate cyclin D-CDK4 complexes stabilized by $\mathrm{p} 21$, by acting as direct CDK4-activating kinases, and also by independently phosphorylating two critical residues of p21 involved in CAK-dependent activation of CDK4.

Inhibition of JNKs decreases cell proliferation, Rb-kinase activity and CDK4 phosphorylation in selected tumor cell lines

We next evaluated whether JNKs are involved in CDK4 activation in vivo. JNKs have various oncogenic and tumor suppressor roles, depending on the context, expression of different JNK isoforms, and even on the approach used to interfere with their expression or activity. ${ }^{48,59-62}$ We selected two cell lines that reportedly depend on JNKs for proliferation: glioblastoma T98G cells ${ }^{44}$ and breast carcinoma MCF-7 cells. ${ }^{47}$ To inhibit JNK activity, we used the anthrapyrazolone SP600125, one of the most studied ATPcompetitive JNK inhibitors. ${ }^{63}$ To circumvent specificity issues that are known with this inhibitor, ${ }^{64}$ we also used the recently developed JNK-IN-8 inhibitor that forms a covalent bond with a conserved cysteine uniquely found in the ATP site of JNKs. ${ }^{65,66}$ Both inhibitors sustainably inhibited c-Jun phosphorylation (Supplementary Figures S3 and S4B) and markedly inhibited the serum-stimulated DNA synthesis in T98G and MCF-7 cells (Figure 4a; Supplementary Figure S4A). 


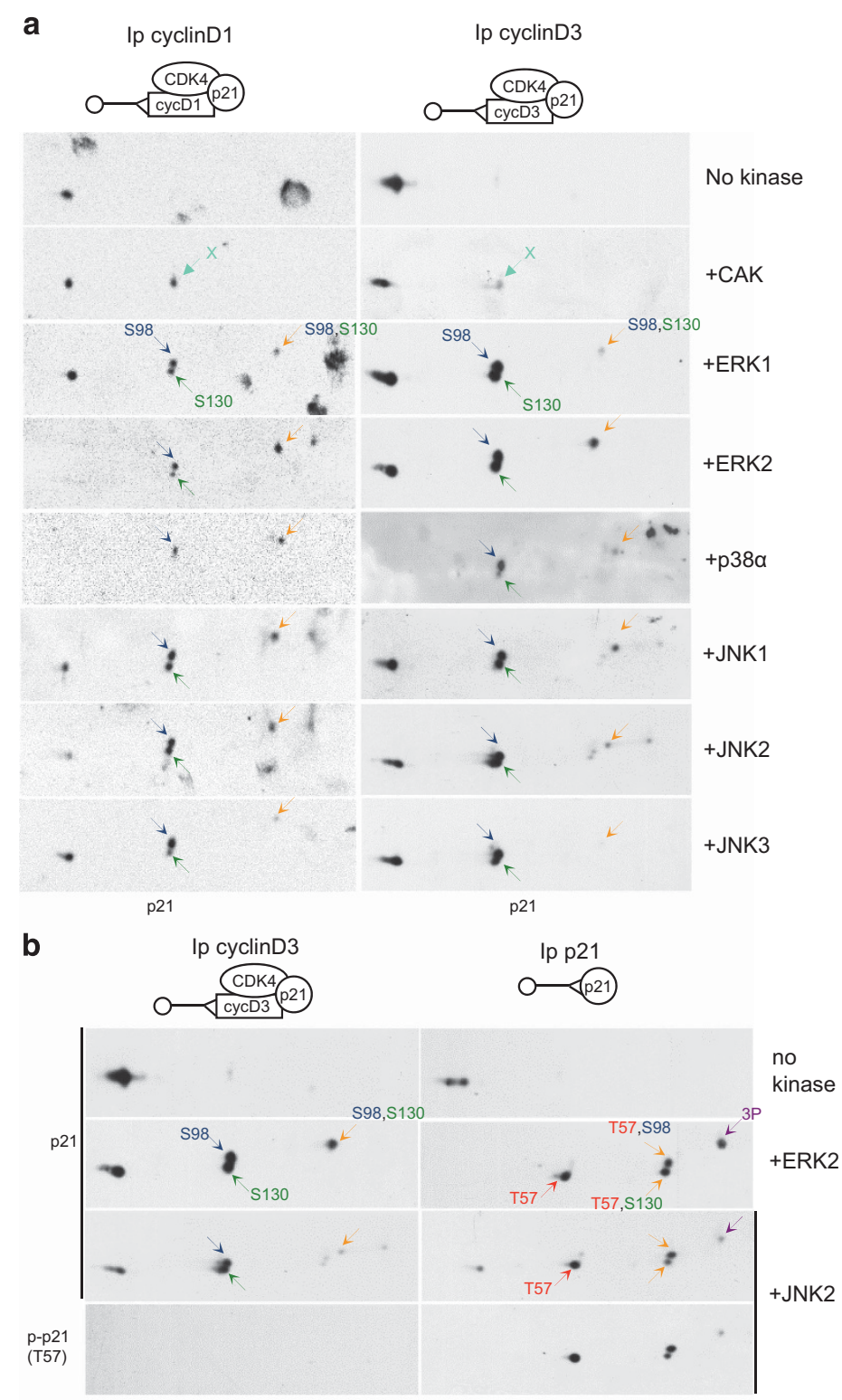

\section{C}

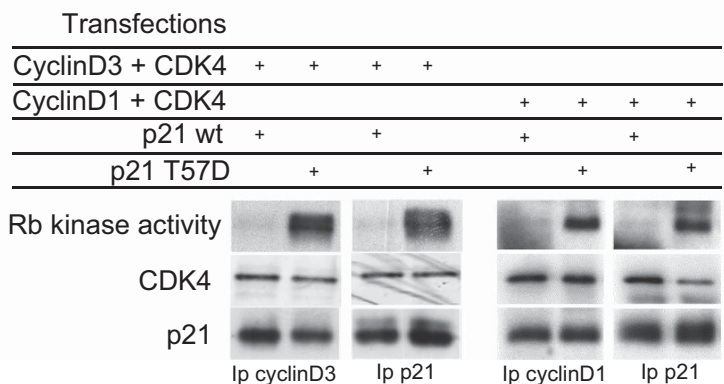

Figure 2. JNKs, ERK1/2 and p38 $\alpha$ phosphorylate p21 in vitro. (a, b) CHO cells were transfected with plasmids encoding CDK4, p21 and cyclin D1 or cyclin D3, or with the p21 plasmid alone (right column in b). Cell lysates were Ip with antibodies against cyclin D1 or cyclin D3 (a, b) or against p21 (b). The immunoprecipitates were incubated with the indicated recombinant kinases and ATP and separated by 2D-gel electrophoresis followed by immunodetection with antibodies against p21 (a, b) or its T57 phosphorylation (p-p21(T57) in b. Colored arrows indicate phosphorylated forms of p21. The experiment in a was reproduced four times using cyclin D1-CDK4-p21 complexes and three times using cyclin D3-CDK4-p21 complexes, with similar results. The experiment in b was reproduced three times with similar results. (c) The T57D phosphomimetic mutation of p21 increases the activity of p21-bound cyclin D1-CDK4 and cyclin D3-CDK4 complexes. CHO cells were transfected with plasmids encoding cyclin D1 or cyclin D3, CDK4 and wt p21 or T57D p21. Cell lysates were Ip with antibodies directed against cyclin D1, cyclin D3 or p21, assayed for their Rb-kinase activity, separated by SDS-PAGE, and immunoblotted with the indicated antibodies. The experiment in c was reproduced three times in cyclin D3-CDK4-p21 complexes and performed twice in cyclin D1-CDK4-p21 complexes, with similar results. 

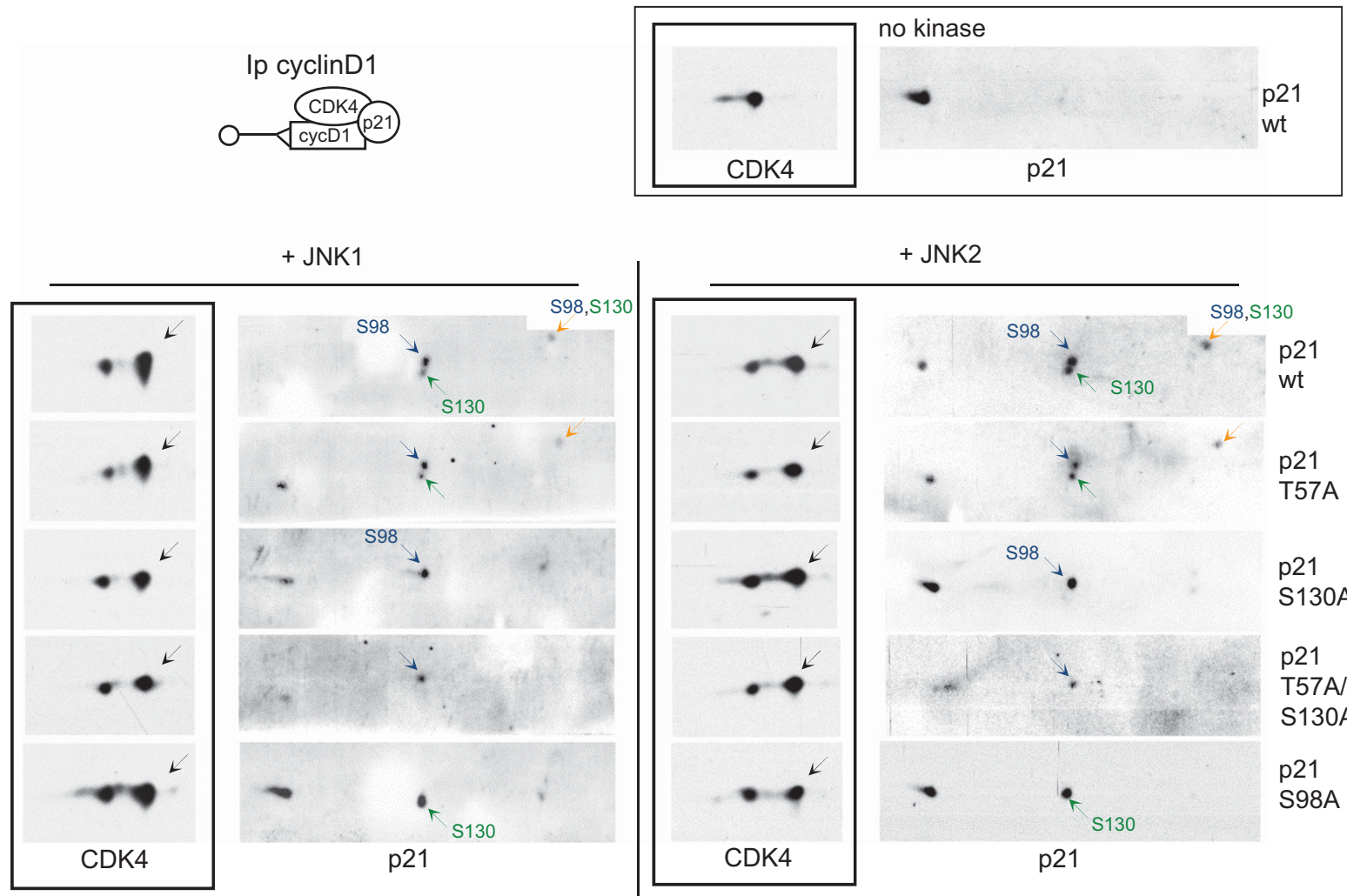

+ JNK1

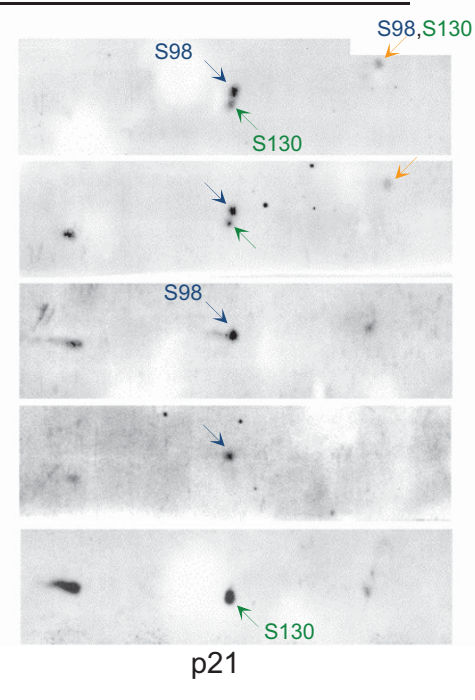

+ JNK2

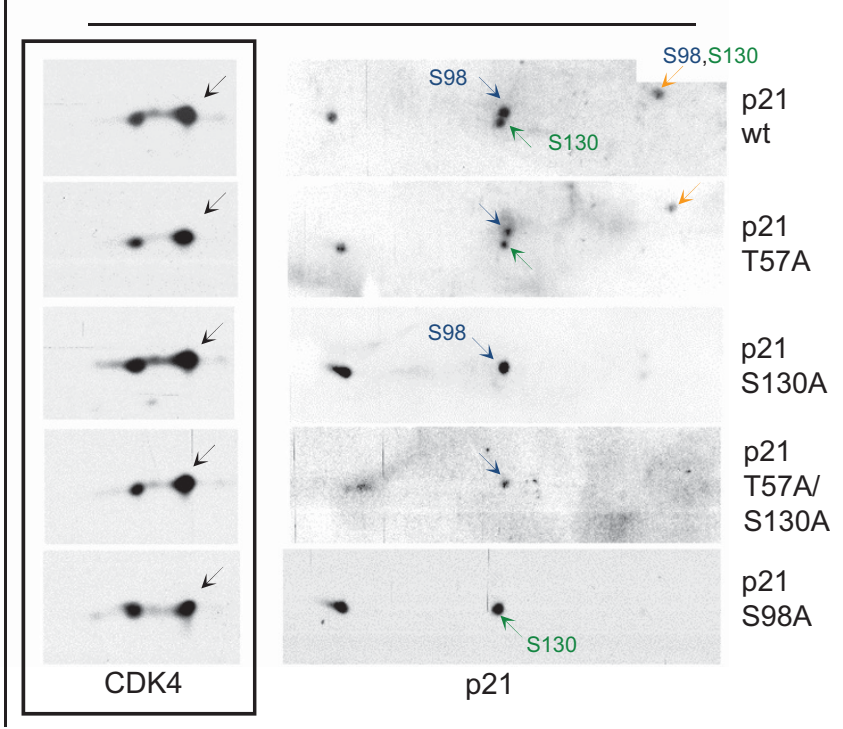

Figure 3. Mutations of p21 phosphorylation sites do not impair the phosphorylation of CDK4 by JNKs in vitro. Extracts of CHO cells transfected with vectors encoding cyclin D1, CDK4 and wild -type (wt) p21 or the indicated phosphorylation mutants of p21 were Ip with cyclin D1 antibody (Ip cyclin D1), and incubated with recombinant JNK1 or JNK2 and ATP. Next, they were separated by 2D-gel electrophoresis followed by immunodetection of CDK4 and p21. Colored arrows indicate phosphorylated forms of p21, black arrows indicate the enhanced abundance of the phosphorylated form of CDK4. This experiment was reproduced with identical results using cyclin D3-CDK4-p21 complexes and incubation with JNK1 or JNK2.

In these experiments, we analyzed the effect of JNK inhibition on the composition, Rb-kinase activity and T172 phosphorylation of CDK4 complexes, which were Ip using antibodies against cyclin D1, cyclin D3, or p21 (Figures 4b and c; Supplementary Figures S4C and D). CDK4 complexes Ip by cyclin D1 and p21 antibodies were studied $8 \mathrm{~h}$ after serum stimulation, that is, before degradation of p21 and cyclin D1 in the S-phase. Cyclin D3-CDK4 complexes become more active later and were studied $16 \mathrm{~h}$ after stimulation. Serum stimulation in T98G and MCF-7 cells much increased the abundance of cyclin D1 and p21 and of CDK4 complexes containing these proteins (Figure 4b; Supplementary Figures S3 and S4C). As we had generally observed, ${ }^{15,23,38}$ the CDK4 complexes Ip by the p21 antibody were as active as those Ip by the cyclin D1 antibody. CDK4 was similarly phosphorylated in both immunoprecipitations (Figure 4c). Serum stimulation also induced the appearance of a p21 form that comigrates exactly with S130-phosphorylated p21 (Figure 4d; Supplementary Figure S4E). These results extend to T98G and MCF-7 cells our observation of a close relationship between the S130 phosphorylation of p21 and the T172 phosphorylation and activation of p21-bound CDK4. ${ }^{23}$

Owing to the inhibition of c-Jun phosphorylation and AP-1 transcriptional activity, ${ }^{43,67}$ SP600125 and JNK-IN-8 were expected to inhibit the serum-stimulated accumulation of cyclin D1. However, cyclin D1 accumulation was only partially affected (Supplementary Figures S3 and S4B). Both JNK inhibitors also partially reduced the accumulation of cyclin D1-CDK4 complexes in the $\mathrm{G} 1$ phase ( $8 \mathrm{~h}$ time point) in T98G cells (Figure $4 \mathrm{~b}$ ). The activity of CDK4 complexes Ip by cyclin D1 and p21 antibodies was even more strongly inhibited in T98G and MCF-7 cells, as shown by comparison and quantitation of detections of Rb-kinase activity and CDK4 in cyclin D1 and p21 immunoprecipitations in Figure 4b and Supplementary Figure S4C. This inhibition correlated with a proportional reduction of the phosphorylation of CDK4 in these complexes (Figure 4c; Supplementary Figure S4D). Both drugs also inhibited the phosphorylation of p21 (Figure 4d; Supplementary Figure S4E).

Intriguingly, such inhibitions by SP600125 and JNK-IN-8 of CDK4 phosphorylation and activity were not observed in cyclin D3 immunoprecipitations, in neither T98G (Figure $4 \mathrm{~b}$ and c) nor MCF-7 cells (Supplementary Figures S4C and D). At the $16 \mathrm{~h}$ time point, cyclin D3-CDK4 complexes were poorly associated with p21. Instead they contained an important presence of p27 (Figure 4b; Supplementary Figure S4C). In vitro, JNK1 was unable to phosphorylate CDK4 in complexes Ip by a p27 antibody from unstimulated T98G cells (Figure 4e). Thus, the different effects of JNK inhibition in the cyclin D1-CDK4 and cyclin D3-CDK4 complexes could depend on their association with p21 or p27. Collectively, the above-described experiments show that two very different JNK inhibitors significantly decrease the entry into cell cycle, and the activity and phosphorylation of p21-bound cyclin D1-CDK4. These findings underlie a major involvement of JNKs in cyclin D1-CDK4 activation in T98G and MCF-7 cells.

We next wanted to verify the effects of JNK inhibition in the activation of ectopic cyclin D1-CDK4-p21 complexes in transfected $\mathrm{CHO}$ cells. Indeed, this experimental cell model was very useful to demonstrate the importance of the proline 173 residue of CDK4, ${ }^{21}$ and to characterize the relationship between T172 phosphorylation of CDK4 and $\mathrm{S} 130$ phosphorylation of p21. ${ }^{23}$ As previously shown in this system, ${ }^{23}$ the phosphorylation of both CDK4 and 
a

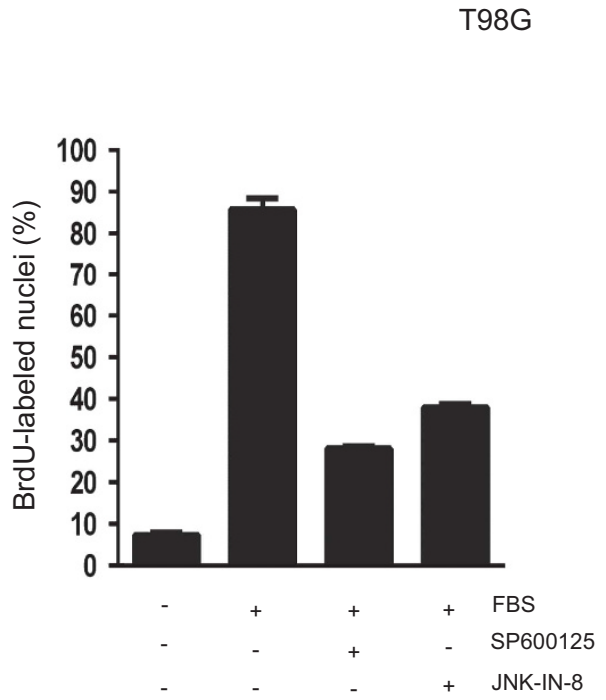

c

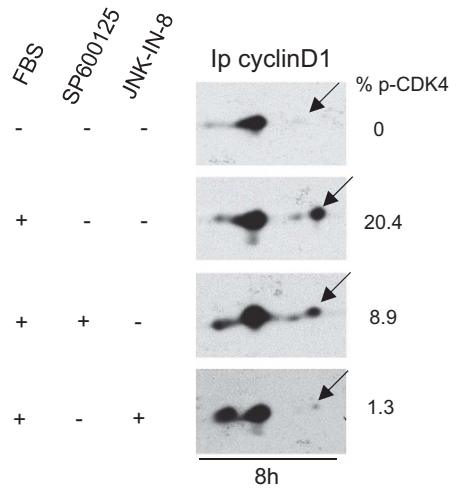

d

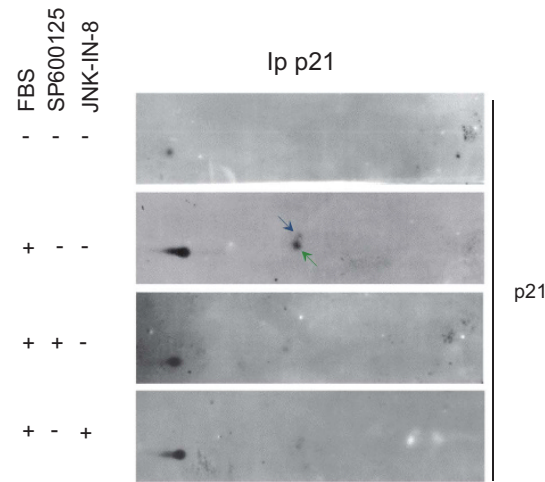

b Ip cyclinD1 Ip cyclinD3 Ip p21

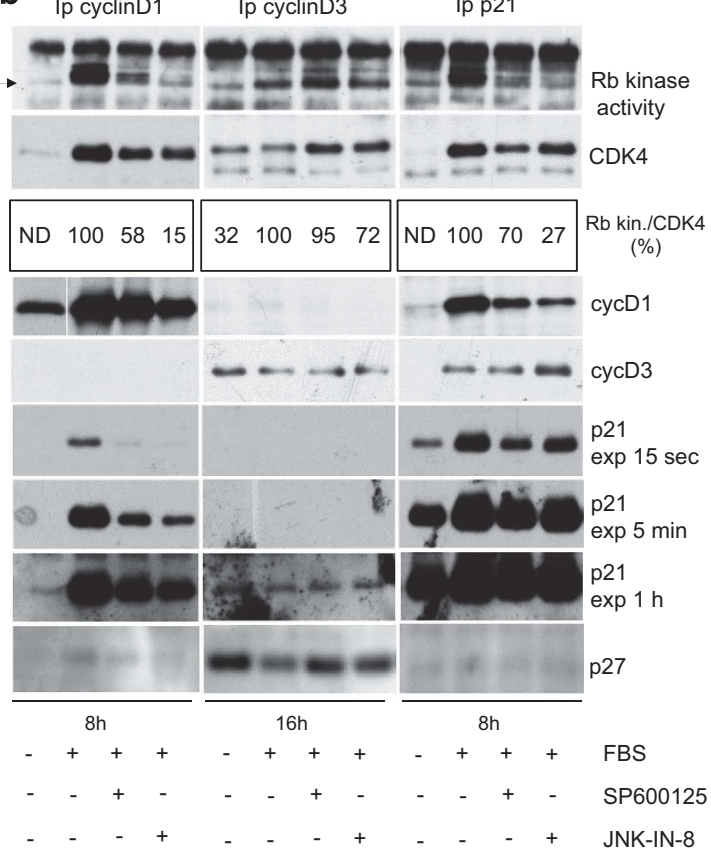

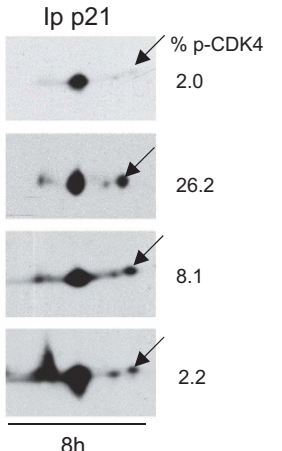

$8 \mathrm{~h}$ e $\quad$ Ip p27

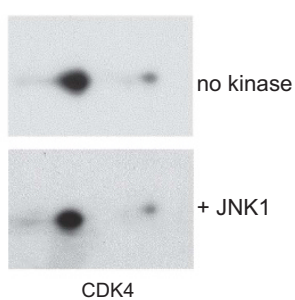

Figure 4. In T98G cells, inhibition of JNKs by SP600125 or JNK-IN-8 decreases DNA synthesis (a), Rb-kinase activity (b), and phosphorylation of CDK4 (c) and p21 (d). (a) T98G cells were stimulated with FBS for $18 \mathrm{~h}$ in the presence or absence of SP600125 or JNK-IN-8. BrdU was present during the last $30 \mathrm{~min}$. The fraction of nuclei having incorporated BrdU was determined (mean+range of duplicate dishes). (b) In the same cell cultures, extracts of cells treated for the indicated times were Ip with anti-cyclin D1, anti-cyclin D3 or anti-p21 antibodies, assayed for Rb-kinase activity, separated by SDS-PAGE and immunoblotted. Rb fragment phosphorylated in vitro at T826 (Rb-kinase activity), CDK4, cyclin D1, cyclin D3, p21 and p27 were detected using specific antibodies. After densitometry quantitation, the Rb-kinase activity was normalized to the amount of co-Ip CDK4 and expressed as \% of the FBS-stimulated condition without JNK inhibitor (Rb Kin./CDK4; ND, values could not be determined because of insufficient CDK4 signal). (c, d) The same immunoprecipitates analyzed in b were separated by 2D-gel electrophoresis followed by immunodetection of CDK4 (c) and p21 (d). The percentage of the T172-phosphorylated form of CDK4 (black arrows) versus the sum of Ip CDK4 forms is determined by densitometry (\% p-CDK4) (c). Arrows in d indicate the phosphorylated form of p21. Results in a-c were reproduced at least five times with SP600125 and three times with JNK-IN-8 in independent experiments, with similar observations. (e) Cell lysates from serum-starved quiescent T98G cells were Ip with p27 antibody (Ip p27), incubated with ATP with or without recombinant JNK1, and separated by 2D-gel electrophoresis followed by CDK4 immunodetection. 
p21 requires that p21 expression is maintained at a concentration that does not exceed the p21-binding capacity of cyclin D-CDK4. This was achieved by diluting the p21 expression plasmid by a factor of 10 relative to expression vectors of cyclin D1 and CDK4 (Figure 5). Because the $\mathrm{S} 130$ phosphorylation of p21 is also performed by CDK2 to allow the CAK/CDK7-dependent phosphorylation of $\mathrm{CDK} 4,{ }^{23}$ we tested the effect of JNK-IN-8 in the presence or absence of R-roscovitine, which inhibits both CDK2 and CDK7. ${ }^{68,69}$ As shown in Figures $5 b$ and $c$, in the absence of roscovitine, JNK-IN-8 partly inhibited the phosphorylation of CDK4 and the activation of cyclin D1-CDK4-p21 complexes. Roscovitine used alone did not reduce the S130 phosphorylation of p21, but it partly inhibited CDK4 phosphorylation (Figure $5 \mathrm{c}$ ). The combination of JNK-IN-8 and roscovitine abrogated the phosphorylation of p21 and induced a more complete inhibition of CDK4 phosphorylation (Figure $5 \mathrm{c}$ ). These results are consistent with a model implying the cooperation of different kinases in the activation of CDK4, including JNKs and CDK2 that allows the activation of CDK4 by CDK7 via S130 phosphorylation of p21.

Cell cycle entry and CDK4 T172 phosphorylation are reduced by specific inhibition of JNK2 in MEFs

To definitively demonstrate the effect of specific inhibition of JNKs on the activation of cyclin D1-CDK4 complexes using a chemical genetic approach, we used MEFs in which both alleles of JNK1 are removed and in which the ATP-binding pocket of JNK2 is enlarged by replacing methionine-108 with a glycine in both alleles (JNK1 $1^{-/-} \mathrm{JNK}^{\mathrm{MG} / \mathrm{MG}}$ ), resulting in sensitization to inhibition by bulky analogs of ATP such as 3MB-PP1. ${ }^{48,70}$ 3MP-PP1 treatment indeed inhibited the serum-stimulated phosphorylation of c-Jun only in $\mathrm{JNK} 1^{-/-} \mathrm{JNK} 2^{\mathrm{MG} / \mathrm{MG}}$ cells but not in wild-type cells (Figure $6 \mathrm{a}$ ) as described. ${ }^{48}$ In wild-type, $\mathrm{JNK}^{-/-} \mathrm{JNK}^{+/+}$and $\mathrm{JNK} 1^{-1-} \mathrm{JNK} 2^{\mathrm{MG} / \mathrm{MG}}$ cell lines, DNA synthesis was maximal after $24 \mathrm{~h}$ of serum stimulation. It was significantly reduced by continuous treatment with SP600125 and even more by JNKIN-8. The same treatment with 3MB-PP1 only inhibited DNA synthesis in $\mathrm{JNK}^{-/-} \mathrm{JNK} 2^{\mathrm{MG} / \mathrm{MG}}$ cells (Figure $6 \mathrm{~b}$ ), confirming that specific JNK2 inhibition decreases cell proliferation. ${ }^{48}$ This effect persisted for at least two successive cell cycles (Figure 6c).

Interestingly, changes in mRNAs of cyclins (including cyclin D1) do not account for the inhibition of cell cycle by specific JNK2 inhibition in $\mathrm{JNK}^{-/-} \mathrm{JNK} 2^{\mathrm{MG} / \mathrm{MG}}$ cells. ${ }^{48}$ CDK4 phosphorylation was analyzed in cyclin D1 immunoprecipitates from the three cell lines. After 2D-gel electrophoresis, CDK4 was immunodetected using antibodies directed against total CDK4 or T172phosphorylated CDK4. 3MB-PP1 decreased the proportion of the T172-phosphorylated form of cyclin D1-bound CDK4 only in JNK1 ${ }^{-1-}$ JNK2 ${ }^{\mathrm{MG} / \mathrm{MG}}$ cells (Figure 7 ). JNK2 is thus a positive regulator of T172 phosphorylation of cyclin D1-CDK4, acting at least in part as a direct CDK4 kinase according to our in vitro analyses.

\section{DISCUSSION}

Whether only one CDK-activating kinase is responsible for the T-loop phosphorylation of the different cell cycle CDKs in animal cells has been intensely debated for two decades. ${ }^{16,23,33,34,39,71-74}$ As summarized in the Introduction, many observations are difficult to reconcile with the concept of only one CAK for all the cell cycle CDKs including CDK4. ${ }^{16}$ However, a chemical genetic approach to selectively inhibit CDK7 activity demonstrated in HCT116 cells a strong involvement of CDK7 in the activating phosphorylation of both CDK4 and CDK6, ${ }^{23,33}$ as well as other CDKs. ${ }^{41}$ To explain the specific regulation of CDK4 phosphorylation, Fisher's group showed that CDK7 needs to be phosphorylated on its T-loop at T170 to be able to phosphorylate CDK4, and claimed that this phosphorylation (by an undefined kinase) is induced by mitogenic signaling. ${ }^{33}$ However, in the same cells, a thorough analysis by 2D-gel separation of cyclin H-CDK7 and detection by a T170phosphospecific antibody showed us that all the cyclin $\mathrm{H}$-bound CDK7 was phosphorylated at T170, even in serum-deprived cell conditions, and that Ip CDK7 was constitutively active when assayed on cyclin D3-CDK4 (Supplementary Figure S10 in Bisteau et $\left.a . .,{ }^{23}\right)$. Instead, we observed that CDK7-dependent phosphorylation of CDK4 depends on S130 phosphorylation of cyclin D/ CDK4-bound p21 by other active CDK4 and CDK2 complexes (the activity of which depends on CDK7). ${ }^{23}$ This situation generates positive-feedback loops to amplify and sustain CDK4 activation, $\mathrm{Rb}$ inactivation and $\mathrm{R}$ point passage. ${ }^{23}$ This raised the question of the initiating mechanisms that engage this positive-feedback system, and we proposed that other PDK(s) could be responsible for the initial CDK7-independent phosphorylation of CDK4 and/or p21 in response to mitogenic stimulation. ${ }^{16,21,23}$

Here, we identified JNK1, JNK2 and possibly JNK3 as such initiating CDK4-activating kinases and demonstrated in selected tumor cell lines, MEFs and transfected $\mathrm{CHO}$ cells that inhibition of JNKs, including specific inhibition of JNK2 activity by a chemical genetic approach, ${ }^{48}$ reduced the phosphorylation and activation of cyclin D1-CDK4 complexes and cell cycle entry. This in vivo effect of JNK inhibitors is very specific because the phosphorylation and activation of cyclin D3-CDK4 complexes were unaffected. While CAK (cyclin H-CDK7-Mat1) is unable to phosphorylate the T-loop of cyclin-CDK4 complexes when they are stabilized by unphosphorylated p21, JNKs did it. This activity of JNKs was also specific as other related PDKs, including ERK1 and ERK2 (this study) or the different cyclin complexes of CDK2, CDK4 or $\mathrm{CDK}^{23}$ cannot phosphorylate CDK4 in the same in vitro conditions. The specificity of the phosphorylation of p21-bound CDK4 by JNKs could be because of the reported interaction of JNKs with both p21 and CDK4, as JNK1 readily phosphorylated cyclin D3CDK4 bound to p21, but much less efficiently when cyclin D3CDK4 was not associated to p21 (Figure 1c), and not at all when this CDK4 complex was bound to p27 (Figure 4e). Therefore, JNK1 and JNK2 might be specialized in the activation of cyclin D-CDK4 complexes that are stabilized by p21.

In addition to directly phosphorylating p21-bound CDK4 independently of phosphorylations of p21, the JNKs and other MAPKs (including ERK1, ERK2 and p38a) phosphorylated p21 at its three S/T-P motifs, in agreement with previous reports. ${ }^{75-77}$ The S130 phosphorylation of p21 observed in the cyclin D1-CDK4 complex is also catalyzed by CDK2, ${ }^{23,78,79}$ and CDK4 and CDK6. ${ }^{23}$ We found this phosphorylation to be required for CDK7dependent phosphorylation and activation of p21-bound cyclin DCDK4. ${ }^{23}$ The T57 phosphorylation of p21 in its CDK-binding domain, performed in vitro by JNKs, ERK $1 / 2$ and $\mathrm{p} 38 \mathrm{a}$, might also be critical in CDK4 activation. Indeed, we previously observed that the phosphomimetic T57D mutation facilitates the phosphorylation of p21-bound CDK4 by CAK/CDK7, ${ }^{23}$ and we observed here that the T57D mutation neutralizes the inhibitory effect of p21 on both the T172 phosphorylation and activity of p21-bound cyclin D-CDK4 complexes. S130A and S130A/T57A mutations of p21 were previously reported to block cell cycle progression at the G1/ $\mathrm{S}$ transition. ${ }^{77,80}$ In T98G cells, phosphorylations of p21 by ERK1 and ERK2 at both S130 and T57 might also explain the partial dependence of CDK4 phosphorylation and activity on MEK activity. ${ }^{19}$ Like others, ${ }^{75}$ we failed to detect an abundant presence of the T57 phosphorylation in vivo (negative data not shown), because this site is inaccessible for phosphorylation in the p21 stabilized in cyclin D-CDK4 complexes (Figure 2b), and possibly because of technical limitations (insufficient reactivity of the T57phosphospecific p21 antibody and partly overlapping migration of T57-monophosphorylated p21 and more abundant S130phosphorylated p21 in 2D-gels). By contrast, the S130 phosphorylation is the most abundant phosphorylation of p21 in the G1 phase. ${ }^{23}$ We observed that JNK inhibition in vivo prevented the 
a

\begin{tabular}{|c|c|c|c|c|c|c|c|c|}
\hline Transfections & & & & & & & & \\
\hline CyclinD1 + CDK4 & + & + & + & + & + & + & + & + \\
\hline p21 & + & + & + & + & & & & \\
\hline p21 1/10 & & & & & & + & + & + \\
\hline
\end{tabular}

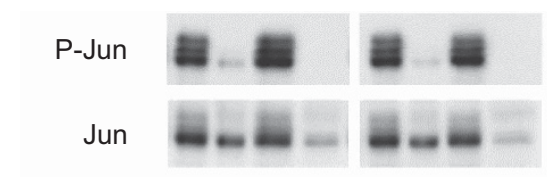

JNK-IN-8 - $\quad+\quad-\quad+\quad-\quad+\quad+$

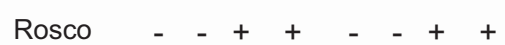

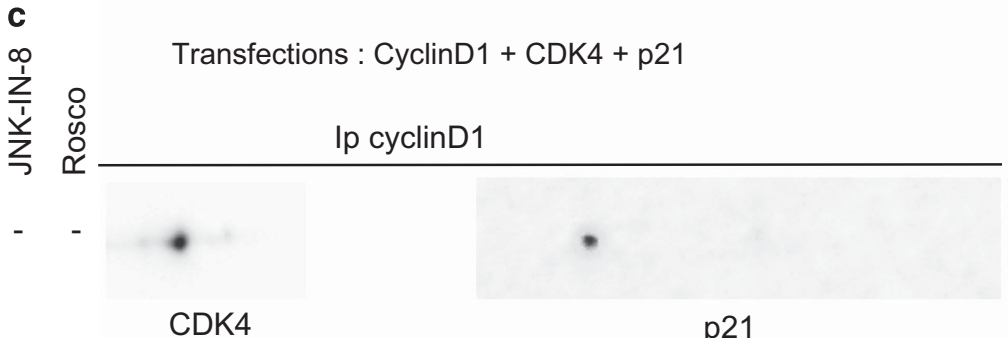

CDK4
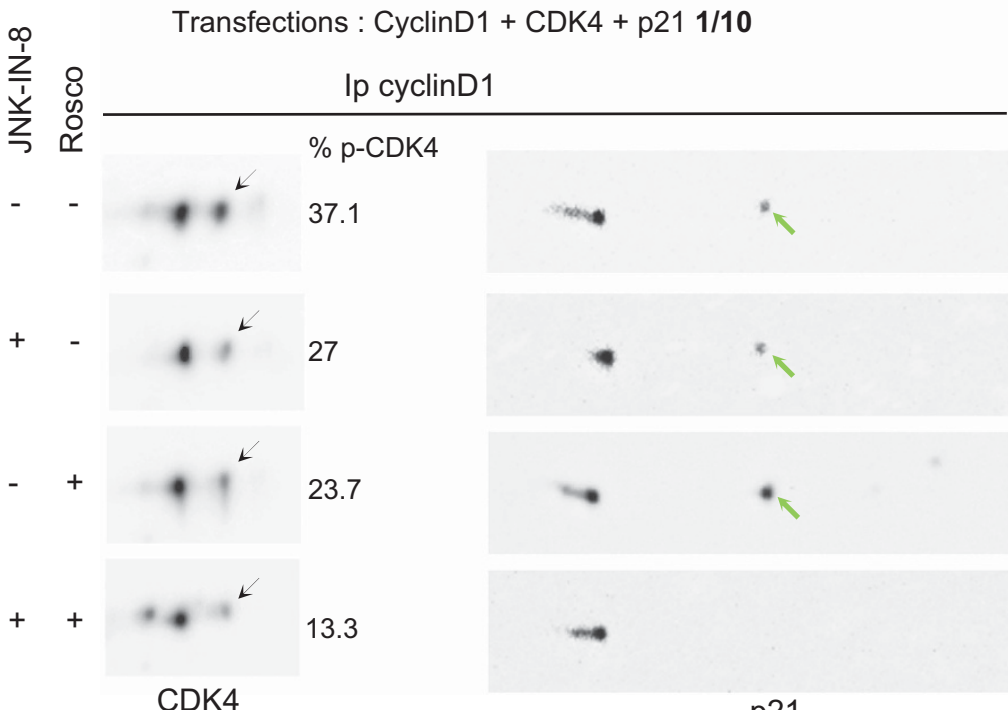

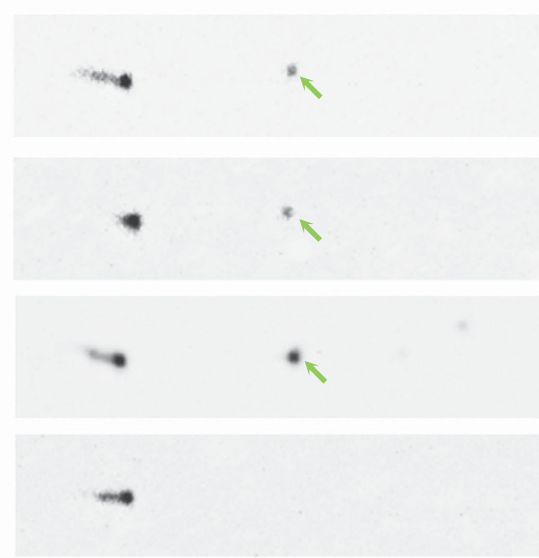

p21
Rb kinase activity

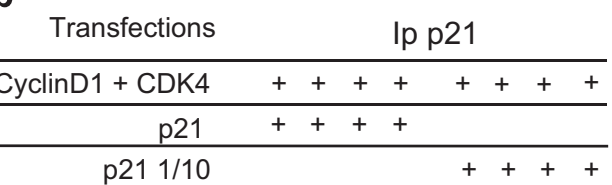

CDK4

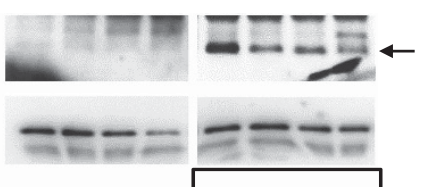

cyc D1

p21

JNK-IN-8

ND

$\begin{array}{llll}100 & 37 & 60 & 32\end{array}$
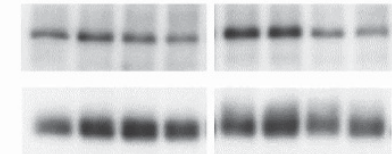

Rosco

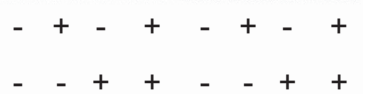

CDK4

7.1

Figure 5. In transfected $\mathrm{CHO}$ cells, JNK inhibition and CDK2/CDK7 inhibition by R-roscovitine decrease the activity of p21-bound cyclin D1-CDK4 and phosphorylation of both p21 and CDK4. CHO cells were transfected with plasmids encoding cyclin D1 and CDK4 together with p21 either at high (p21) or low (p21 1/10) expression level, in the absence or presence of JNK-IN-8 and/or R-roscovitine (Rosco). As previously shown in these experimental conditions, ${ }^{23}$ a low expression of p21 permits the activity and phosphorylation of cyclin D-CDK4 and the S130 phosphorylation of p21, whereas higher expression of p21 inhibits phosphorylations of both p21 and CDK4. (a) Effect of the inhibitors on c-Jun S63 phosphorylation (P-Jun) analyzed by immunoblotting from cell lysates (WCE). (b) These cell lysates were Ip with anti-p21 antibody, assayed for their Rb-kinase activity, separated by SDS-PAGE and immunoblotted with the indicated antibodies. (c) The same cell lysates were Ip with anti-cyclin D1 or antip21 antibodies and separated by 2D-gel electrophoresis followed by immunodetection of CDK4 and p21. Black arrows, T172-phosphorylated CDK4; green arrows, S130-phosphorylated form of p21 as previously identified. ${ }^{23}$ In a-c chemiluminescence images of blots were captured with a Solo7S camera (Vilber-Lourmat, Marne-la-Vallée, France) and quantified using the Bio1D software (Vilber-Lourmat). The Rb-kinase activity was normalized to the amount of co-lp CDK4 and expressed as \% of the condition without inhibitor (Rb kin./CDK4 in b). The percentage of the T172-phosphorylated form of CDK4 versus the sum of Ip CDK4 forms is also determined (\% p-CDK4 in c). 
a

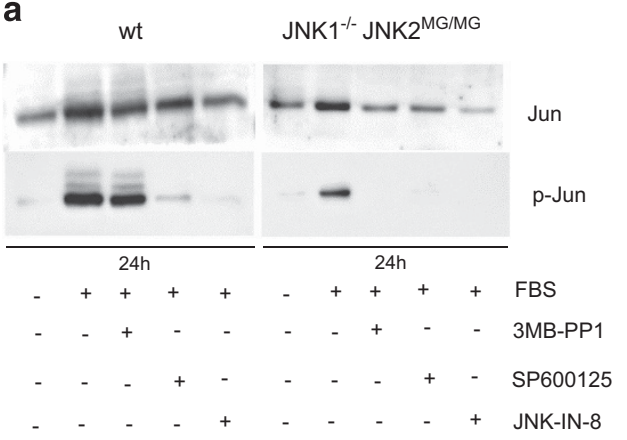

C

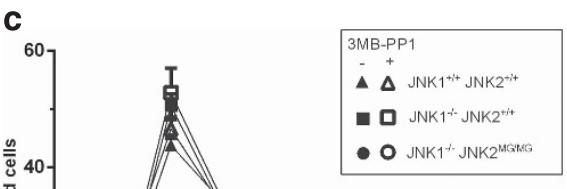

b

wt
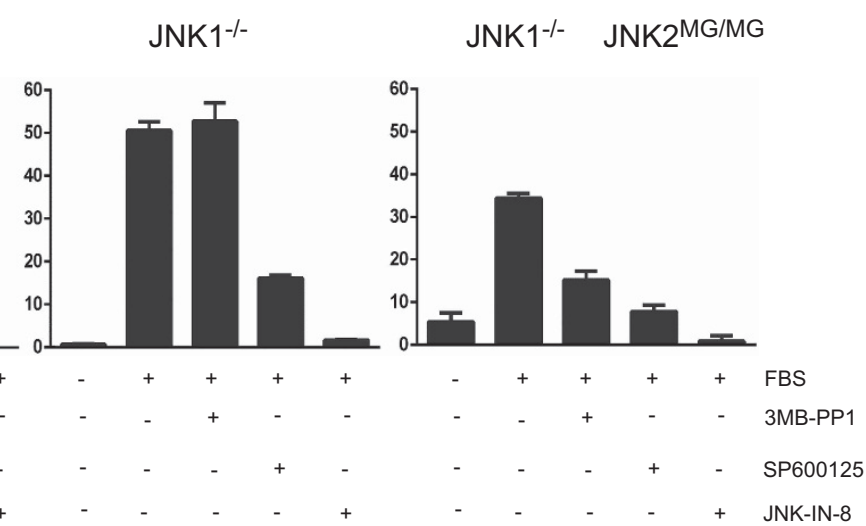

Figure 6. Specific inhibition of JNK2 prevents DNA synthesis in $\mathrm{JNK}^{-1-} \mathrm{JNK} 2^{\mathrm{MG} / \mathrm{MG}}$ MEFs. (a) Synchronized wild-type (wt), JNK1 ${ }^{-/-}$and JNK1 ${ }^{-/-}$ JNK2 ${ }^{\text {MG/MG }}$ MEFs were stimulated with FBS for $24 \mathrm{~h}$ in the presence or absence of 3MB-PP1, SP600125 or JNK-IN-8. Western blotting analysis of c-Jun phosphorylation at S63 with the indicated antibodies was performed. (b, c) DNA synthesis in the same cultures was evaluated by a 30 min incubation with BrdU, $24 \mathrm{~h}$ after stimulation (b) or at the indicated time points (c). The fraction of nuclei having incorporated BrdU was determined (mean+range of duplicate dishes).

appearance of this phosphorylated form in both T98G and MCF-7 cells. Interestingly, S130 phosphorylation of p21 is also critical because it forms a phosphodegron recognized by the SCF/Skp2 ubiquitin ligase complex to signal the proteasomal degradation of cyclin/CDK-bound p21, which is required for facilitating CDK2 activation and S-phase entry ${ }^{78,79,81}$ (this mechanism would not prevent the accumulation of S130-phosphorylated p21 in the G1 phase because at this stage Skp2 levels are kept low by degradation catalyzed by APC-Cdh1). ${ }^{81}$

The T172 phosphorylation of CDK4 is particularly unstable, ${ }^{23,33}$ indicating that it requires a sustained activity of the responsible kinase(s). The present data, together with our previous observations, suggest a model in which different CDK4-activating kinases, including JNKs and CAK/CDK7, would act successively and cooperate to initiate, maintain and amplify the activation of CDK4, and to generate the cell cycle decision. This model is illustrated and detailed in Figure 8 and its legend. By separately phosphorylating CDK4 at T172 and p21 at S130 and possibly at T57, JNKs would initiate feedback mechanisms involving further phosphorylation at S130 of cyclin/CDK4-bound p21 by CDK4/6 and CDK2. These phosphorylations of p21 would then facilitate the CDK7-dependent phosphorylation at T172 of the bulk of CDK4 complexes stabilized by p21. Other mechanisms should exist in other cell systems and regulations, presumably involving other CDK4-activating kinase(s), to explain the p21-independent activation of cyclin D3-CDK4-p27 complexes observed in the cAMP-dependent cell cycle of thyrocytes ${ }^{18,37,38}$ and the high phosphorylation level of CDK4 in p27-bound cyclin D3-CDK4 complexes in other cells including T98G cells. ${ }^{15,18,19,82}$

JNKs exert oncogenic actions in several cancers including hepatocellular carcinoma. ${ }^{50,62,83,84}$ Positive effects on cell proliferation and escape from senescence were well described in
$\mathrm{MEFs}^{48,52,85,86}$ and during liver regeneration. ${ }^{87}$ They are especially observed in tumoral cells and in in vivo cancer models in which high constitutive basal activity of JNKs is observed, due to either expression of long JNK2 isoforms (a2), which dimerize and transautophosphorylate, $^{88-91}$ or overexpression of the JNK activating kinases MKK4 and MKK7..$^{1,92,93}$ In general, mechanisms of cell cycle regulation by JNKs were thought to result from c-Jun phosphorylation and stabilization, AP-1 transcriptional activation and cyclin D1 transcriptional induction, ${ }^{43,48,60,61,83,87}$ p21 downregulation, ${ }^{50}$ or transcriptional downregulation of $\operatorname{Trp} 53 .{ }^{86}$ Here, we provide evidence that JNKs also directly control the activation and activity of cyclin D1-CDK4 complexes by phosphorylating both CDK4 and p21. As CDK4 is emerging as a new major target for cancer therapy, our present findings together with the availability of new classes of JNK inhibitory drugs, ${ }^{62,65}$ suggest the possibility of specifically targeting JNKs to control deregulated CDK4 activation in some cancers.

\section{MATERIALS AND METHODS}

Cell cultures, JNKs inhibition and BrdU incorporation

T98G and MCF-7 cells were authenticated by profiling of short tandem repeats (STR, performed by ATCC before submission of the revised manuscript). All cell lines were tested for mycoplasma contamination. T98G and $\mathrm{CHO}$ cells were obtained and cultured as described. ${ }^{15,23}$ T98G cells were serum-starved and their growth was stimulated with 15\% FBS. MCF-7 cells were obtained and cultured as described ${ }^{94}$ in DMEM supplemented with antibiotics, $1 \%$ non-essential aminoacids, $6 \mathrm{ng} / \mathrm{ml}$ insulin and 5\% FBS. After starvation for 3 days in DMEM without phenol red, FBS and insulin, they were growth-stimulated in medium supplemented with $5 \% \mathrm{FBS}, 6 \mathrm{ng} / \mathrm{ml}$ insulin and $10^{-7} \mathrm{M} \beta$-estradiol. Primary wild-type, JNK1 $1^{-1-}$ and JNK1 $1^{-1-}$ JNK2 ${ }^{\mathrm{MG} / \mathrm{MG}}$ MEFs were isolated in the Roger J. Davis Lab ${ }^{48}$ and cultured in DMEM supplemented with antibiotics, $10 \%$ heat-inactivated FBS and 
wt
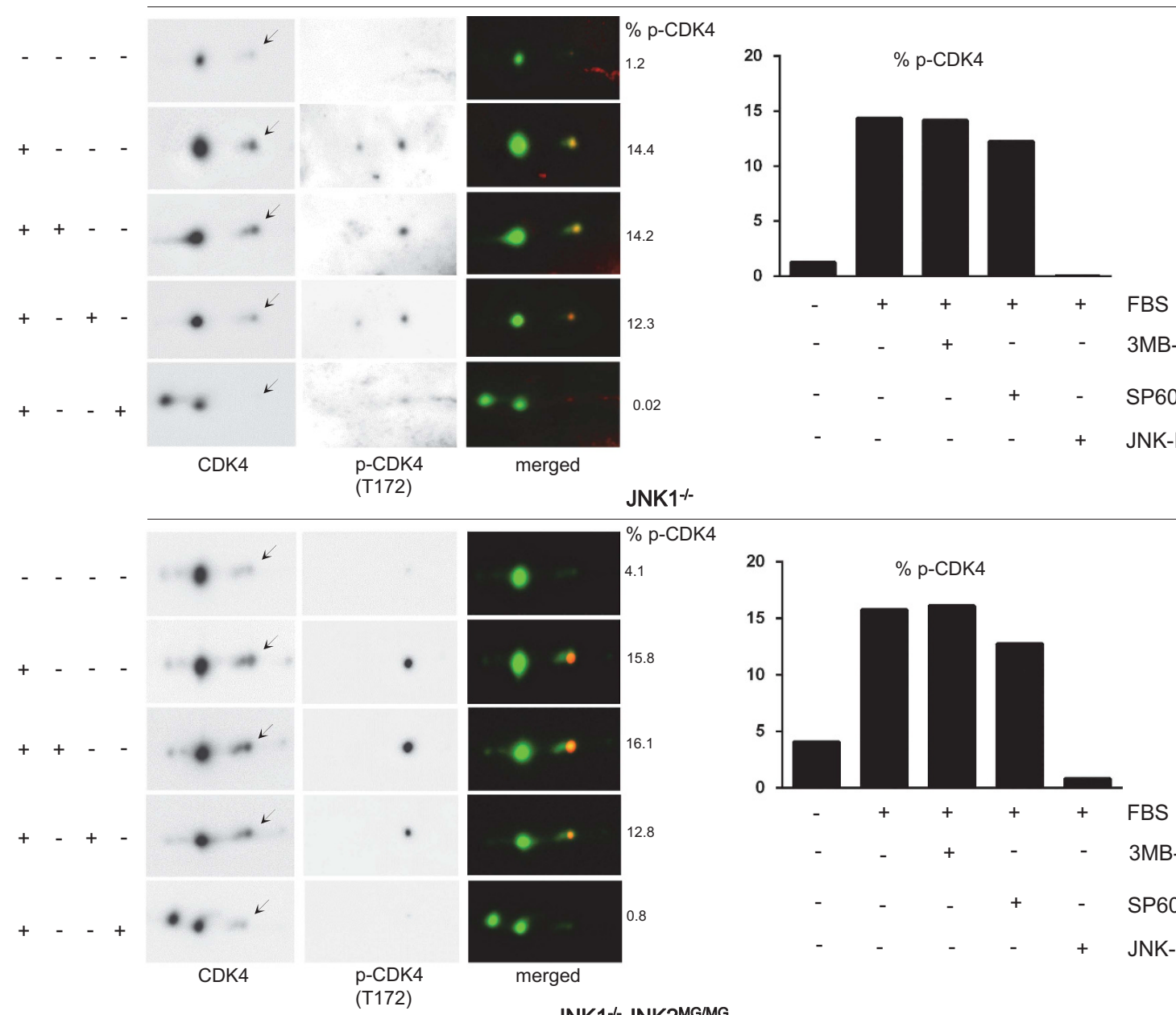

merged
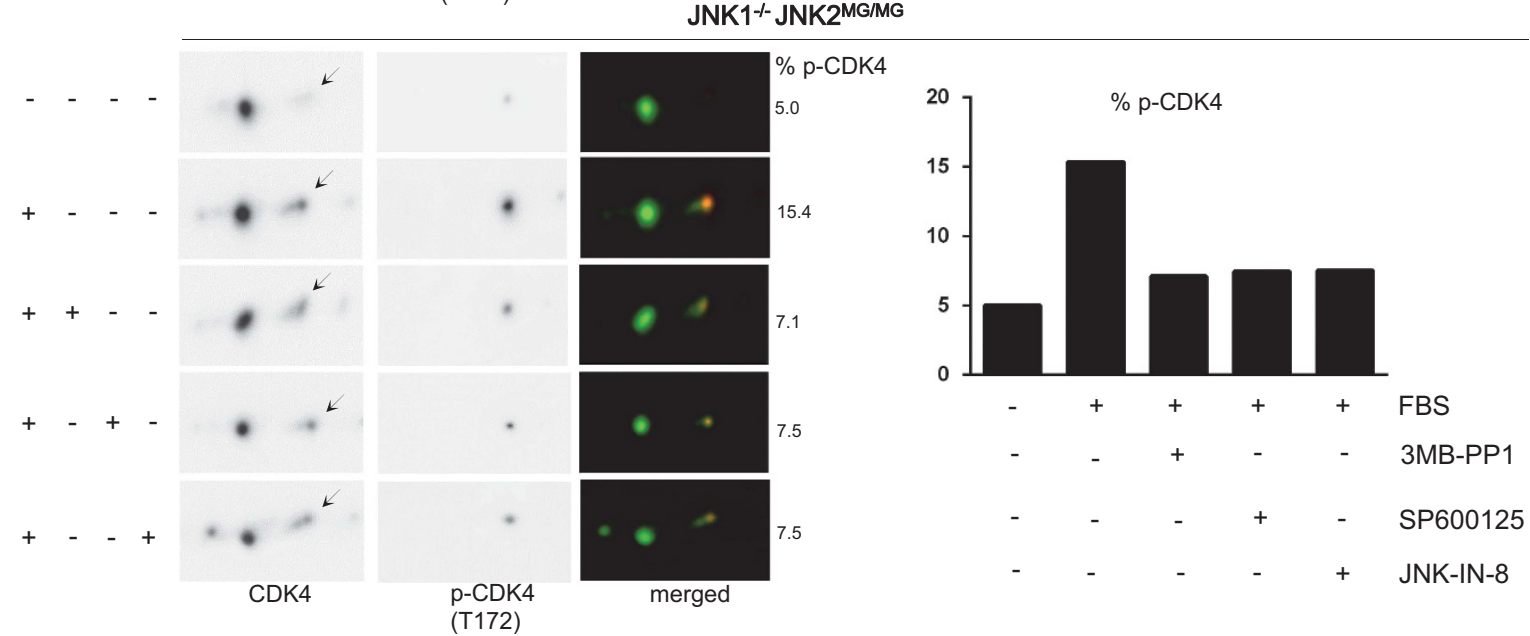

Figure 7. Specific inhibition of JNK2 decreases T172 phosphorylation of CDK4 in JNK1 $1^{-/-} \mathrm{JNK} 2^{\mathrm{MG} / \mathrm{MG}}$ MEFs. From the cultures described in Figure 5, extracts of synchronized wild-type (wt), JNK1 ${ }^{-1-}$, and $\mathrm{JNK} 1^{-1-} \mathrm{JNK} 2^{\mathrm{MG} / \mathrm{MG}}$ MEFs stimulated with FBS for $24 \mathrm{~h}$ in the presence or absence of 3MB-PP1, SP600125 or JNK-IN-8 were Ip with anti-cyclin D1, and separated by 2D-gel electrophoresis. Immunodetection was done with antibodies directed against CDK4 or its T172 phosphorylation ( $p$-CDK4(T172)). Chemiluminescence images of blots were captured with a Vilber-Lourmat Solo7S camera and quantified using the Bio1D software (Vilber-Lourmat). The coincidence of the detections is shown by their superposition after conversion to green or red (respectively) using Photoshop software (merged, Adobe Systems Inc., San Jose, CA, USA). The percentage of the T172-phosphorylated form of CDK4 (arrows) versus the sum of Ip CDK4 forms is indicated (\% P-CDK4) and shown in the bar graphs. Results with the three inhibitors were reproduced in independent experiments three times in wt MEFs and twice in JNK $1^{-1-}$ JNK2 $2^{\mathrm{MG} / \mathrm{MG}}$ MEFs. 


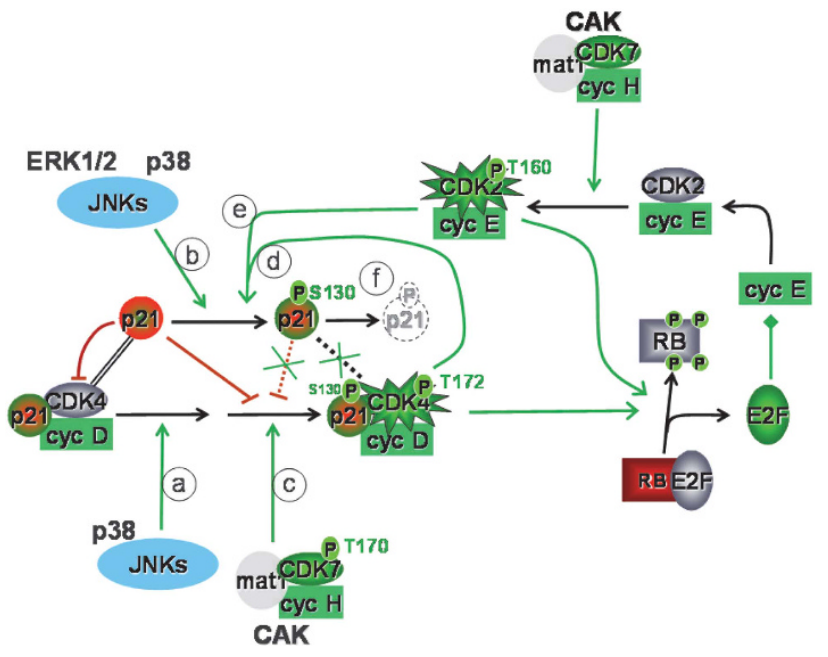

Figure 8. Model integrating the present observations with our previous analysis of the involvement of CDK7 and S130 phosphorylation of p21 in CDK4 activation. ${ }^{23}$ This model includes the evidence that p21 stabilizes cyclin D-CDK4 complexes but, at a higher stoichiometry of p21 binding, inhibits their activity. ${ }^{25}$ The model also considers that the T172 phosphorylation of CDK4 is particularly unstable, requiring a sustained activity of CDK4activating kinases. ${ }^{23,33}$ While CAK/CDK7 cannot phosphorylate CDK4 bound to unphosphorylated p21, JNKs and possibly p38 $\alpha$ do it and thus are able to initiate the activation of p21-stabilized cyclin D1-CDK4 complexes by direct phosphorylation of CDK4 (arrow a). JNKs, p38 $\alpha$ and ERK1/2 also phosphorylate p21 on S130 (arrow b) and possibly T57 (not represented), which could facilitate the CDK7-dependent phosphorylation of CDK4 ${ }^{23}$ (arrow c). The activation of CDK4 is then amplified and maintained by $\mathrm{S} 130$ phosphorylation of p21 by other active complexes of CDK4 (arrow d) and CDK2 (arrow e). As demonstrated by others, ${ }^{78,79}$ S130 phosphorylation of p21 subsequently leads to increased degradation of p21 (arrow f), which facilitates CDK2 activation. Cooperation between JNKs and other signal transduction kinases (arrows a and b), CAK (arrow c) and cyclin-dependent kinases (arrows $d$ and e) would thus initiate, amplify and maintain the activation of CDK4 to permit the passage through the R point. Green/red colors indicate a final positive/negative influence on $R$ point passage.

$1 \mathrm{~mm} \mathrm{~N}$-acetylcysteine. MEFs were synchronized by incubation for $36 \mathrm{~h}$ with $2 \mathrm{~mm}$ thymidine, released for $36 \mathrm{~h}$ in $10 \%$ FBS medium, then starved for $60 \mathrm{~h}$ in serum-free medium, and then stimulated with $10 \% \mathrm{FBS}$. Inhibitory drugs were dissolved in DMSO and used at the following concentrations: 25 M SP600125 (S5567, Sigma, St Louis, MO, USA), $10 \mu \mathrm{m}$ JNK-IN-8 (inhibitor XVI, sc-364745 from Santa Cruz Biotechnology, Dallas, TX, USA), $20 \mu \mathrm{M}$ R-roscovitine (R7772, Sigma), $10 \mu \mathrm{M}$ 3MB-PP1 (529582, Calbiochem, San Diego, CA, USA). Controls were treated with DMSO. DNAreplicating cells were identified by incubation with BrdU for $30 \mathrm{~min}$ and counted under the microscope. ${ }^{95}$

\section{Transfections}

$\mathrm{CHO}$ cells were transfected for $48 \mathrm{~h}$ as described ${ }^{23}$ in $9-\mathrm{cm}$ petridishes with $4 \mu \mathrm{g}$ pcDNA3 vector encoding myc-tagged CDK4, $4 \mu \mathrm{g}$ pcDNA3 vector encoding Xpress-cyclin D3, or $4 \mu \mathrm{g}$ pCS2 vector encoding cyclin D1-flag, and $4 \mu \mathrm{g}$ PE vector encoding p21 or its mutants. In experiments with a $1 / 10$ dilution of $\mathrm{p} 21$ vector, $0.4 \mu \mathrm{g}$ of vector encoding wt p21 was used.

\section{Immunoprecipitations}

Co-immunoprecipitations were performed as described ${ }^{15,18}$ using monoclonal antibodies against cyclin D1 (EPR2241, Abcam, Cambridge, UK), cyclin D3 (DCS-28, Neomarkers, Fremont, CA, USA) or polyclonal antibody against p21 (C-19, sc-397 from Santa Cruz Biotechnology).
Rb-kinase assay

As described, ${ }^{15,18} \mathrm{Ip}$ complexes were incubated with $2 \mathrm{~mm}$ ATP and $0.3 \mu \mathrm{g}$ of a aa773-928 fragment of human $\mathrm{Rb}$ for $15 \mathrm{~min}$ at $30{ }^{\circ} \mathrm{C}$ with constant agitation. The incubation mixture was separated by SDS-PAGE and T826 phosphorylation of the Rb fragment, CDK4, cyclin D1, cyclin D3, p21 and p27 were immunodetected using antibodies listed below.

In vitro phosphorylation assay of CDK4 and p21

Cyclin D1-CDK4-p21 and cyclin D3-CDK4-p21 or p21 alone were Ip from $\mathrm{CHO}$ cells transfected as above and used as substrate for the assay. The immunoprecipitates were washed three times with NP-40 buffer ${ }^{15,18}$ and once with CAK buffer ( $80 \mathrm{~mm} \beta$-glycerophosphate $\mathrm{pH} 7.3,15 \mathrm{~mm} \mathrm{MgCl}$, $20 \mathrm{~mm}$ EGTA, $5 \mathrm{~mm}$ dithiothreitol). ${ }^{36}$ The immunoprecipitates were then incubated for $1 \mathrm{~h}$ at $30^{\circ} \mathrm{C}$ with constant agitation in $50 \mu \mathrm{l} \mathrm{CAK}$ buffer with the indicated concentrations of ATP and $1 \mu \mathrm{g}$ of recombinant active kinases: CDK7/cyclin H/MAT1 (WAB0365-B, Millipore, Billerica, MA, USA), JNK1-MAPK8 (11CBS-0166G), JNK2-MAPK9 (10CBS-0674E), JNK3-MAPK10 (11CBS-0377B), p38a-MAPK14 (10CBS-0523 J), ERK2-MAPK1 (09CBS-0516E; all from Carna Biosciences, Natick, MA, USA) or ERK1-MAPK3 (PV3311, Invitrogen, Carlsbad, CA, USA).

\section{D-gel electrophoresis}

As described, ${ }^{15,23,82}$ the washed Ip complexes were denatured in a solution containing $7 \mathrm{~m}$ urea and $2 \mathrm{~m}$ thiourea. Proteins were separated by isoelectric focusing on linear gradient strips pH 5-8 (BioRad, Hercules, CA, USA) or pH 3-10 (Amersham Biosciences, GE Healthcare Europe, Diegem, Belgium), then by molecular weight in $12.5 \%$ SDS-PAGE gels. Next, they were immunoblotted using CDK4 H-22 antibody (sc-601, Santa Cruz), p21 C-19 antibody (sc-397, Santa Cruz), a non-commercialized polyclonal phosphospecific CDK4 (T172) antibody (from Cell Signaling Technology, Danvers, MA, USA) that we had fully characterized, ${ }^{15,21}$ or a phosphospecific p21(T57) antibody (AP3190a, Abgent, San Diego, CA, USA).

\section{Immunoblot analyses}

SDS-PAGE separations of equal amounts of whole cell extract proteins or immunoprecipitates ${ }^{15}$ were immunodetected using the following antibodies: cyclin D1 (DCS-6, sc-20044), cyclin D3 (DCS-22, sc-56307), CDK4 (DCS-31, sc-56277), p21 (C-19, sc-397), p27 (DCS-72, sc-56338) and c-Jun (H-79, sc-1694) (all from Santa Cruz), p21 (12D1, \#2947 from Cell Signalling Technology), phospho c-Jun (Ser63) (\#2361 from Cell Signalling Technology or MA5-15115 from Thermo-Fisher Scientific, Waltham, MA, USA) or phospho Rb (Thr826) (EPR5351, ab133446 from Abcam).

Both in 2D-gel and 1D-gel immunoblot analyses, chemiluminescence detections on films were quantitated using a GS-800 densitometer and the Quantity-One software (BioRad). Chemiluminescence images of blots were also captured with a Vilber-Lourmat Solo7S camera and quantified using the Bio1D software (Vilber-Lourmat).

\section{CONFLICT OF INTEREST}

The authors declare no conflict of interest.

\section{ACKNOWLEDGEMENTS}

The p21 expression plasmids and MCF-7 cells were provided by Ludger Hengst (Innsbruck University) and Geert Berx (Ghent University), respectively. Amin Bredan edited the English text. We thank Professor Jacques E. Dumont (Université Libre de Bruxelles) for continued interest and support. This study was supported by WELBIO (Walloon Excellence in Lifesciences and Biotechnology), the Belgian Foundation against Cancer (Grant 2014-130), the FRS-FNRS Grants T003813F and J.0002.16 and the Docteur JP Naets Fund (managed by the King Baudouin Foundation). BC was a fellow of the FRIA and is supported by the Fondation Rose et Jean Hoguet, the Fonds David et Alice Van Buuren and the Fondation Jaumotte-Demoulin, JMP is a fellow of the Télévie and PPR is a Senior Research Associate of the FRS-FNRS.

\section{REFERENCES}

1 Malumbres M, Barbacid M. Cell cycle, CDKs and cancer: a changing paradigm. Nat Rev Cancer 2009; 9: 153-166. 
2 Satyanarayana A, Kaldis P. Mammalian cell-cycle regulation: several Cdks, numerous cyclins and diverse compensatory mechanisms. Oncogene 2009; 28: 2925-2939.

3 Sherr CJ. D-type cyclins. Trends Biochem Sci 1995; 20: 187-190.

4 Bartek J, Bartkova J, Lukas J. The retinoblastoma protein pathway and the restriction point. Curr Opin Cell Biol 1996; 8: 805-814.

5 Bockstaele L, Coulonval K, Kooken H, Paternot S, Roger PP. Regulation of CDK4. Cell Div 2006; 1: 25.

6 Lundberg AS, Weinberg RA. Functional inactivation of the retinoblastoma protein requires sequential modification by at least two distinct cyclin-cdk complexes. Mol Cell Biol 1998; 18: 753-761.

7 Yao G, Lee TJ, Mori S, Nevins JR, You L. A bistable Rb-E2F switch underlies the restriction point. Nat Cell Biol 2008; 10: 476-482.

8 Choi YJ, Li X, Hydbring P, Sanda T, Stefano J, Christie AL et al. The requirement for cyclin d function in tumor maintenance. Cancer Cell 2012; 22: 438-451.

9 Puyol M, Martin A, Dubus P, Mulero F, Pizcueta P, Khan G et al. A synthetic lethal interaction between $\mathrm{K}$-Ras oncogenes and $\mathrm{Cdk} 4$ unveils a therapeutic strategy for non-small cell lung carcinoma. Cancer Cell 2010; 18: 63-73.

10 Asghar U, Witkiewicz AK, Turner NC, Knudsen ES. The history and future of targeting cyclin-dependent kinases in cancer therapy. Nat Rev Drug Discov 2015; 14: $130-146$.

11 Turner NC, Ro J, Andre F, Loi S, Verma S, Iwata H et al. Palbociclib in hormonereceptor-positive advanced breast cancer. N Engl J Med 2015; 373: 209-219.

12 Hamilton E, Infante JR. Targeting CDK4/6 in patients with cancer. Cancer Treat Rev 2016; 45: 129-138.

13 Sherr CJ, Beach D, Shapiro Gl. Targeting CDK4 and CDK6: from discovery to therapy. Cancer Discov 2016; 6: 353-367.

14 Kato JY, Matsuoka M, Strom DK, Sherr CJ. Regulation of cyclin D-dependent kinase 4 (cdk4) by cdk4-activating kinase. Mol Cell Biol 1994; 14: 2713-2721.

15 Bockstaele L, Kooken H, Libert F, Paternot S, Dumont JE, de Launoit $\mathrm{Y}$ et al. Regulated activating Thr172 phosphorylation of cyclin-dependent kinase 4(CDK4): its relationship with cyclins and CDK 'inhibitors'. Mol Cell Biol 2006; 26: 5070-5085.

16 Paternot S, Bockstaele L, Bisteau X, Kooken H, Coulonval K, Roger PP. Rb inactivation in cell cycle and cancer: The puzzle of highly regulated activating phosphorylation of CDK4 versus constitutively active CDK-activating kinase. Cell Cycle 2010; 9: 689-699.

17 Coulonval K, Kooken H, Roger PP. Coupling of T161 and T14 phosphorylations protects cyclin B-CDK1 from premature activation. Mol Biol Cell 2011; 22: 3971-3985.

18 Paternot S, Coulonval K, Dumont JE, Roger PP. Cyclic AMP-dependent phosphorylation of cyclin D3-bound CDK4 determines the passage through the cell cycle restriction point in thyroid epithelial cells. J Biol Chem 2003; 278: 26533-26540.

19 Paternot S, Roger PP. Combined inhibition of MEK and mammalian target of rapamycin abolishes phosphorylation of cyclin-dependent kinase 4 in glioblastoma cell lines and prevents their proliferation. Cancer Res 2009; 69: 4577-4581.

20 Rocha AS, Paternot S, Coulonval K, Dumont JE, Soares P, Roger PP. Cyclic AMP inhibits the proliferation of thyroid carcinoma cell lines through regulation of CDK4 phosphorylation. Mol Biol Cell 2008; 19: 4814-4825.

21 Bockstaele L, Bisteau X, Paternot S, Roger PP. Differential regulation of cyclindependent kinase 4 (CDK4) and CDK6, evidence that CDK4 might not be activated by CDK7, and design of a CDK6 activating mutation. Mol Cell Biol 2009; 29: 4188-4200.

22 Blancquaert S, Wang L, Paternot S, Coulonval K, Dumont JE, Harris TE et al. Cyclic AMP-dependent activation of mammalian target of rapamycin (mTOR) in thyroid cells. Implication in mitogenesis and activation of CDK4. Mol Endocrinol 2010; 24: 1453-1468.

23 Bisteau X, Paternot S, Colleoni B, Ecker K, Coulonval K, De Groote P et al. CDK4 T172 phosphorylation is central in a CDK7-dependent bidirectional CDK4/CDK2 interplay mediated by p21 phosphorylation at the restriction point. PLoS Genet 2013; 9: e1003546.

24 Abbas T, Dutta A. p21 in cancer: intricate networks and multiple activities. Nat Rev Cancer 2009; 9: 400-414.

25 LaBaer J, Garrett MD, Stevenson LF, Slingerland JM, Sandhu C, Chou HS et al. New functional activities for the p21 family of CDK inhibitors. Genes Dev 1997; 11: 847-862.

26 Sherr CJ, Roberts JM. CDK inhibitors: positive and negative regulators of G1-phase progression. Genes Dev 1999; 13: 1501-1512.

27 Blain SW, Montalvo E, Massague J. Differential interaction of the cyclin-dependent kinase (Cdk) inhibitor p27Kip1 with cyclin A-Cdk2 and cyclin D2-Cdk4. J Biol Chem 1997; 272: 25863-25872.

28 Sheaff RJ, Groudine M, Gordon M, Roberts JM, Clurman BE. Cyclin E-CDK2 is a regulator of p27Kip1. Genes Dev 1997; 11: 1464-1478.
29 Grimmler M, Wang Y, Mund T, Cilensek Z, Keidel EM, Waddell MB et al. Cdkinhibitory activity and stability of p27Kip1 are directly regulated by oncogenic tyrosine kinases. Cell 2007; 128: 269-280.

30 Jakel H, Peschel I, Kunze C, Weinl C, Hengst L. Regulation of p27 (Kip1) by mitogen-induced tyrosine phosphorylation. Cell Cycle 2012; 11: 1910-1917.

31 Ray A, James MK, Larochelle S, Fisher RP, Blain SW. p27Kip1 inhibits cyclin D-cyclin-dependent kinase 4 by two independent modes. Mol Cell Biol 2009; 29: 986-999.

32 Fisher RP. Secrets of a double agent: CDK7 in cell-cycle control and transcription. J Cell Sci 2005; 118: 5171-5180.

33 Merzel Schachter M, Merrick KA, Larochelle S, Hirschi A, Zhang C et al. A Cdk7-Cdk4 T-loop phosphorylation cascade promotes $\mathrm{G} 1$ progression. Mol Cell 2013; 50: 250-260.

34 Kaldis P. The cdk-activating kinase (CAK): from yeast to mammals. Cell Mol Life Sci 1999; 55: 284-296.

35 Tassan JP, Schultz SJ, Bartek J, Nigg EA. Cell cycle analysis of the activity, subcellular localization, and subunit composition of human CAK (CDK-activating kinase). J Cell Biol 1994; 127: 467-478.

36 Matsuoka M, Kato JY, Fisher RP, Morgan DO, Sherr CJ. Activation of cyclindependent kinase 4 (cdk4) by mouse MO15-associated kinase. Mol Cell Biol 1994; 14: 7265-7275.

37 Paternot S, Arsenijevic T, Coulonval K, Bockstaele L, Dumont JE, Roger PP. Distinct specificities of pRb phosphorylation by CDK4 activated by cyclin D1 or cyclin D3: differential involvement in the distinct mitogenic modes of thyroid epithelial cells. Cell Cycle 2006; 5: 61-70.

38 Paternot S, Dumont JE, Roger PP. Differential utilization of cyclin D1 and cyclin D3 in the distinct mitogenic stimulations of human thyrocytes by growth factors and TSH. Mol Endocrinol 2006; 20: 3279-3292.

39 Kaldis P, Russo AA, Chou HS, Pavletich NP, Solomon MJ. Human and yeast cdk-activating kinases (CAKs) display distinct substrate specificities. Mol Biol Cell 1998; 9: 2545-2560.

40 Larochelle S, Batliner J, Gamble MJ, Barboza NM, Kraybill BC, Blethrow JD et al. Dichotomous but stringent substrate selection by the dual-function Cdk7 complex revealed by chemical genetics. Nat Struct Mol Biol 2006; 13: 55-62.

41 Larochelle S, Merrick KA, Terret ME, Wohlbold L, Barboza NM, Zhang C et al. Requirements for Cdk7 in the assembly of Cdk1/cyclin B and activation of Cdk2 revealed by chemical genetics in human cells. Mol Cell 2007; 25: 839-850.

42 Ubersax JA, Ferrell JE Jr. Mechanisms of specificity in protein phosphorylation. Nat Rev Mol Cell Biol 2007; 8: 530-541.

43 Davis RJ. Signal transduction by the JNK group of MAP kinases. Cell 2000; 103 : 239-252.

44 Potapova O, Gorospe M, Bost F, Dean NM, Gaarde WA, Mercola D et al. c-Jun $\mathrm{N}$-terminal kinase is essential for growth of human T98G glioblastoma cells. J Biol Chem 2000; 275: 24767-24775.

45 Yang YM, Bost F, Charbono W, Dean N, McKay R, Rhim JS et al. C-Jun NH(2)terminal kinase mediates proliferation and tumor growth of human prostate carcinoma. Clin Cancer Res 2003; 9: 391-401.

46 Cui J, Wang Q, Wang J, Lv M, Zhu N, Li Y et al. Basal c-Jun NH2-terminal protein kinase activity is essential for survival and proliferation of T-cell acute lymphoblastic leukemia cells. Mol Cancer Ther 2009; 8: 3214-3222.

47 Parra E, Ferreira J. Knockdown of the c-Jun-N-terminal kinase expression by siRNA inhibits MCF-7 breast carcinoma cell line growth. Oncol Rep 2010; 24: 1339-1345.

48 Jaeschke A, Karasarides M, Ventura JJ, Ehrhardt A, Zhang C, Flavell RA et al. JNK2 is a positive regulator of the cJun transcription factor. Mol Cell 2006; 23: 899-911.

49 Cui J, Han SY, Wang C, Su W, Harshyne L, Holgado-Madruga M et al. c-Jun NH(2)terminal kinase 2alpha2 promotes the tumorigenicity of human glioblastoma cells. Cancer Res 2006; 66: 10024-10031.

50 Hui L, Zatloukal K, Scheuch H, Stepniak E, Wagner EF. Proliferation of human HCC cells and chemically induced mouse liver cancers requires JNK1-dependent p21 downregulation. J Clin Invest 2008; 118: 3943-3953.

51 Khatlani TS, Wislez M, Sun M, Srinivas H, Iwanaga K, Ma L et al. c-Jun N-terminal kinase is activated in non-small-cell lung cancer and promotes neoplastic transformation in human bronchial epithelial cells. Oncogene 2007; 26: 2658-2666.

52 Cellurale C, Sabio G, Kennedy NJ, Das M, Barlow M, Sandy P et al. Requirement of c-Jun $\mathrm{NH}(2)$-terminal kinase for Ras-initiated tumor formation. Mol Cell Biol 2011; 31: 1565-1576.

53 Shim J, Lee H, Park J, Kim H, Choi EJ. A non-enzymatic p21 protein inhibitor of stress-activated protein kinases. Nature 1996; 381: 804-806.

54 Patel R, Bartosch B, Blank JL. p21WAF1 is dynamically associated with JNK in human T-lymphocytes during cell cycle progression. J Cell Sci 1998; 111: 2247-2255.

55 Xue Y, Ramaswamy NT, Hong X, Pelling JC. Association of JNK1 with p21 waf1 and p53: modulation of JNK1 activity. Mol Carcinog 2003; 36: 38-44.

56 Chen J, Saha P, Kornbluth S, Dynlacht BD, Dutta A. Cyclin-binding motifs are essential for the function of p21CIP1. Mol Cell Biol 1996; 16: 4673-4682. 
57 Lin J, Reichner C, Wu X, Levine AJ. Analysis of wild-type and mutant p21WAF-1 gene activities. Mol Cell Biol 1996; 16: 1786-1793.

58 Welcker M, Lukas J, Strauss M, Bartek J. p21WAF1/CIP1 mutants deficient in inhibiting cyclin-dependent kinases (CDKs) can promote assembly of active cyclin D/CDK4(6) complexes in human tumor cells. Cancer Res 1998; 58: 5053-5056.

59 Bode AM, Dong Z. The functional contrariety of JNK. Mol Carcinog 2007; 46: 591-598.

60 Wagner EF, Nebreda AR. Signal integration by JNK and p38 MAPK pathways in cancer development. Nat Rev Cancer 2009; 9: 537-549.

61 Tournier C. The 2 faces of JNK signaling in cancer. Genes Cancer 2013; 4: 397-400.

62 Bubici C, Papa S. JNK signalling in cancer: in need of new, smarter therapeutic targets. Br J Pharmacol 2014; 171: 24-37.

63 Bennett BL, Sasaki DT, Murray BW, O'Leary EC, Sakata ST, Xu W et al. SP600125, an anthrapyrazolone inhibitor of Jun N-terminal kinase. Proc Natl Acad Sci USA 2001; 98: 13681-13686.

64 Bain J, Plater L, Elliott M, Shpiro N, Hastie CJ, McLauchlan H et al. The selectivity of protein kinase inhibitors: a further update. Biochem J 2007; 408: 297-315.

65 Zhang T, Inesta-Vaquera F, Niepel M, Zhang J, Ficarro SB, Machleidt T et al. Discovery of potent and selective covalent inhibitors of JNK. Chem Biol 2012; 19: 140-154.

66 Fallahi-Sichani M, Moerke NJ, Niepel M, Zhang T, Gray NS, Sorger PK. Systematic analysis of BRAF(V600E) melanomas reveals a role for JNK/c-Jun pathway in adaptive resistance to drug-induced apoptosis. Mol Syst Biol 2015; 11: 797.

67 Shaulian E, Karin M. AP-1 in cell proliferation and survival. Oncogene 2001; 20 2390-2400.

68 Bach S, Knockaert M, Reinhardt J, Lozach O, Schmitt S, Baratte B et al. Roscovitine targets, protein kinases and pyridoxal kinase. I Biol Chem 2005; 280: 31208-31219.

69 Wesierska-Gadek J, Borza A, Komina O, Maurer M. Impact of roscovitine, a selective CDK inhibitor, on cancer cells: bi-functionality increases its therapeutic potential. Acta Biochim Pol 2009; 56: 495-501.

70 Ventura JJ, Hubner A, Zhang C, Flavell RA, Shokat KM, Davis RJ. Chemical genetic analysis of the time course of signal transduction by JNK. Mol Cell 2006; 21 701-710.

71 Solomon MJ. The function(s) of CAK, the p34cdc2-activating kinase. Trends Biochem Sci 1994; 19: 496-500.

72 Liu Y, Wu C, Galaktionov K. p42, a novel cyclin-dependent kinase-activating kinase in mammalian cells. J Biol Chem 2004; 279: 4507-4514.

73 Wohlbold L, Larochelle S, Liao JC, Livshits G, Singer J, Shokat KM et al. The cyclin-dependent kinase (CDK) family member PNQALRE/CCRK supports cell proliferation but has no intrinsic CDK-activating kinase (CAK) activity. Cell Cycle 2006; 5: 546-554.

74 Ganuza M, Saiz-Ladera C, Canamero M, Gomez G, Schneider R, Blasco MA et al. Genetic inactivation of Cdk7 leads to cell cycle arrest and induces premature aging due to adult stem cell exhaustion. EMBO J 2012; 31: 2498-2510.

$75 \mathrm{Kim}$ GY, Mercer SE, Ewton DZ, Yan Z, Jin K, Friedman E. The stress-activated protein kinases p38 alpha and JNK1 stabilize p21(Cip1) by phosphorylation. J Biol Chem 2002; 277: 29792-29802.

76 Zhan J, Easton JB, Huang S, Mishra A, Xiao L, Lacy ER et al. Negative regulation of ASK1 by p21Cip1 involves a small domain that includes Serine 98 that is phosphorylated by ASK1 in vivo. Mol Cell Biol 2007; 27: 3530-3541.

77 Hwang CY, Lee C, Kwon KS. Extracellular signal-regulated kinase 2-dependent phosphorylation induces cytoplasmic localization and degradation of p21Cip1. Mol Cell Biol 2009; 29: 3379-3389.

78 Bornstein G, Bloom J, Sitry-Shevah D, Nakayama K, Pagano M, Hershko A. Role of the SCFSkp2 ubiquitin ligase in the degradation of p21Cip1 in S phase. J Biol Chem 2003; 278: 25752-25757.

79 Zhu H, Nie L, Maki CG. Cdk2-dependent Inhibition of p21 stability via a C-terminal cyclin-binding motif. J Biol Chem 2005; 280: 29282-29288.
80 Jarviluoma A, Child ES, Sarek G, Sirimongkolkasem P, Peters G, Ojala PM et al. Phosphorylation of the cyclin-dependent kinase inhibitor p21Cip1 on serine 130 is essential for viral cyclin-mediated bypass of a p21Cip1-imposed G1 arrest. Mol Cell Biol 2006; 26: 2430-2440.

81 Bashir T, Dorrello NV, Amador V, Guardavaccaro D, Pagano M. Control of the SCF (Skp2-Cks1) ubiquitin ligase by the APC/C(Cdh1) ubiquitin ligase. Nature 2004; 428: 190-193.

82 Coulonval K, Bockstaele L, Paternot S, Dumont JE, Roger PP. The cyclin D3-CDK4p27kip 1 holoenzyme in thyroid epithelial cells: activation by TSH, inhibition by TGFbeta, and phosphorylations of its subunits demonstrated by two-dimensional gel electrophoresis. Exp Cell Res 2003; 291: 135-149.

83 Sakurai T, Maeda S, Chang L, Karin M. Loss of hepatic NF-kappa B activity enhances chemical hepatocarcinogenesis through sustained c-Jun $\mathrm{N}$-terminal kinase 1 activation. Proc Natl Acad Sci USA 2006; 103: 10544-10551.

84 Das M, Garlick DS, Greiner DL, Davis RJ. The role of JNK in the development of hepatocellular carcinoma. Genes Dev 2011; 25: 634-645.

85 Tournier C, Hess P, Yang DD, Xu J, Turner TK, Nimnual A et al. Requirement of JNK for stress-induced activation of the cytochrome c-mediated death pathway. Science 2000; 288: 870-874.

86 Das M, Jiang F, Sluss HK, Zhang C, Shokat KM, Flavell RA et al. Suppression of p53-dependent senescence by the JNK signal transduction pathway. Proc Natl Acad Sci USA 2007; 104: 15759-15764.

87 Schwabe RF, Bradham CA, Uehara T, Hatano E, Bennett BL, Schoonhoven R et al. c-Jun-N-terminal kinase drives cyclin D1 expression and proliferation during liver regeneration. Hepatology 2003; 37: 824-832.

88 Tsuiki H, Tnani M, Okamoto I, Kenyon LC, Emlet DR, Holgado-Madruga M et al. Constitutively active forms of c-Jun $\mathrm{NH}$ 2-terminal kinase are expressed in primary glial tumors. Cancer Res 2003; 63: 250-255.

89 Cui J, Holgado-Madruga M, Su W, Tsuiki H, Wedegaertner P, Wong AJ. Identification of a specific domain responsible for JNK2alpha2 autophosphorylation. J Biol Chem 2005; 280: 9913-9920.

90 Nitta RT, Chu AH, Wong AJ. Constitutive activity of JNK2 alpha2 is dependent on a unique mechanism of MAPK activation. J Biol Chem 2008; 283: 34935-34945.

91 Nitta RT, Del Vecchio CA, Chu AH, Mitra SS, Godwin AK, Wong AJ. The role of the c-Jun N-terminal kinase 2-alpha-isoform in non-small cell lung carcinoma tumorigenesis. Oncogene 2011; 30: 234-244.

92 Wang L, Pan Y, Dai JL. Evidence of MKK4 pro-oncogenic activity in breast and pancreatic tumors. Oncogene 2004; 23: 5978-5985.

93 Finegan KG, Tournier C. The mitogen-activated protein kinase kinase 4 has a prooncogenic role in skin cancer. Cancer Res 2010; 70: 5797-5806.

94 Paternot S, Colleoni B, Bisteau X, Roger PP. The CDK4/CDK6 inhibitor PD0332991 paradoxically stabilizes activated cyclin D3-CDK4/6 complexes. Cell Cycle 2014; 13: 2879-2888.

95 Roger PP, Baptist M, Dumont JE. A mechanism generating heterogeneity in thyroid epithelial cells: suppression of the thyrotropin/cAMP-dependent mitogenic pathway after cell division induced by cAMP-independent factors. $J$ Cell Biol 1992; 117: 383-393.

(c) $\Theta$ This work is licensed under a Creative Commons AttributionNonCommercial-NoDerivs 4.0 International License. The images or other third party material in this article are included in the article's Creative Commons license, unless indicated otherwise in the credit line; if the material is not included under the Creative Commons license, users will need to obtain permission from the license holder to reproduce the material. To view a copy of this license, visit http:// creativecommons.org/licenses/by-nc-nd/4.0/

(c) The Author(s) 2017

Supplementary Information accompanies this paper on the Oncogene website (http://www.nature.com/onc) 